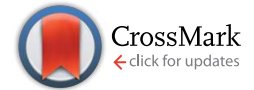

Cite this: RSC Adv., 2017, 7, 5733
Received 6th November 2016 Accepted 20th December 2016

DOI: $10.1039 / c 6 r a 26390 a$

www.rsc.org/advances

\section{Swollen liquid crystals (SLCs): a versatile template for the synthesis of nano structured materials}

\begin{abstract}
Sunil Dutt, ${ }^{* a}$ Prem Felix Siril ${ }^{b}$ and Samy Remita ${ }^{\text {cd }}$
Liquid crystal (LCS) is the state of matter that exhibits properties between a conventional liquid and solid crystals. Liquid crystals mainly can be classified into two types: thermotropic and lyotropic liquid crystals. A thermotropic liquid crystal shows properties that are dependent on temperature conditions. On the other hand in lyotropic liquid crystals (LLCS), the amphiphiles are dissolved in a solvent and exhibit liquid crystalline properties in certain concentration ranges. In the literature, lot of reviews have been presented on thermotropic and lyotropic liquid crystals (LLCS). But nowadays, swollen liquid crystals (SLCS) have become a much more important area of research because of their easily tunable properties, their stability and versatility of the system. Swollen liquid crystals (SLCS) consist of infinite liquid crystalline non polar cylinders organized on a hexagonal lattice in a polar medium and are prepared with the proper ratios of salted water and non polar solvents with cationic or anionic or non ionic surfactants and co surfactants i.e. water : oil : surfactant : cosurfactant. In this review article, we will briefly discuss the synthesis of swollen liquid crystals (SLCs), factors affecting their stability, different kinds of nanomaterials such as metallic, bimetallic, polymeric nanostructures synthesized inside swollen liquid crystals (SLCs) using different methods and the effect of swollen liquid crystal (SLC) confinement on the final morphology of nanomaterials with their potential applications.
\end{abstract}

anstitute of Materials Science and Nanotechnology (UNAM), National Nanotechnology Research Center, Bilkent University, Ankara 06800, Turkey. E-mail: sunildutt.iitmandi@gmail.com

${ }^{b}$ School of Basic Sciences, Indian Institute of Technology Mandi, Mandi-175001, Himachal Pradesh, India
'Laboratoire de Chimie Physique, UMR8000, CNRS, Université Paris-Sud 11, Bât. 349, Campus d'Orsay, 15 Avenue Jean Perrin, 91405 Orsay Cedex, France

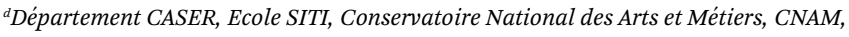
292 rue Saint-Martin, 75141 Paris Cedex 03, France

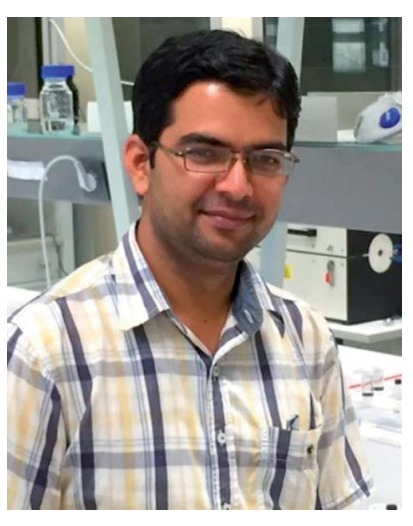

Dr Sunil Dutt received his PhD degree from the Indian Institute of Technology (I.I.T) Mandi, India in 2015. Currently, he is working as a Post-doctoral fellow at the Institute of Materials Science and Nanotechnology (UNAM), National Nanotechnology Research Center, Bilkent University, Ankara, Turkey. He is a recipient of the TUBITAK 2216 Postdoctoral fellowship for International researchers. Before joining UNAM, he worked as a Postdoctoral fellow at I.I.T. Mandi, India. His research interests include synthesis, characterization and application of conducting polymer nanostructures and their nanocomposites for electrochemical sensing, energy storage, catalysis etc.

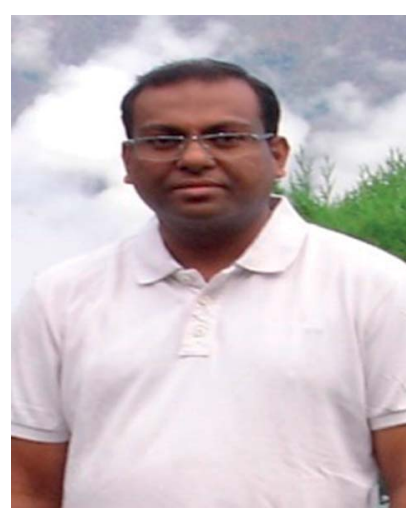

Dr Prem Felix Siril received his PhD degree from DDU Gorakhpur University, India in 2003. He worked as a postdoctoral fellow at the University of Huddersfield, UK and University of Paris-Sud, France. He is a recipient of the Royal Society, UK network fellowship and Marie Curie International Incoming Fellowship. $\mathrm{He}$ is currently working as an Associate Professor at the School of Basic Sciences, IIT Mandi, India. His research interests include synthesis, characterization and application of nanostructures of polymers, noble metals and their composites with pristine graphene. He is also interested in drug nanocrystals and nanodrug delivery. 


\section{Introduction}

The tremendous progress in the field of nano science and nano technology in recent years leads to the development of new materials at the nano scale with improved properties for different applications. But, a major research task is to control the size and shape of bulk materials at the nano level. So different methods were reported in the literature for the synthesis of materials at the nano scale such as membranes, ${ }^{1}$ electrospinning, ${ }^{2,3}$ template assisted, ${ }^{4,5}$ sol-gel, ${ }^{6,7}$ microemulsions, ${ }^{8}$ hydrothermal, sonochemical, microwave methods ${ }^{9}$ etc. There are advantages and disadvantages of these methods. For example, among the template assisted synthetic routes, soft templates are easier and more convenient to use than the hard templates. This is because post synthesis removal of hard templates such as mesoporous silica, anodized aluminium oxide etc. usually require harsh conditions, which may even rupture the prepared nanostructures. ${ }^{10}$ On the other hand soft templates, such as micelles that are formed by the self-assembly of surfactants and polymers can be easily removed by simple washing after the synthesis of nanostructures. ${ }^{11}$

Swollen liquid crystals (SLCs) have attracted much more attention in the recent years due to their potential applications in many technological important research areas. This surfactant mesophases act as very useful and versatile templates for the synthesis of nanostructured materials. Swollen liquid crystals (SLCs) are formed by a quaternary mixture of surfactant, cosurfactant, water and oil.

Nanostructures can be synthesized using both aqueous phase and organic phase of swollen liquid crystals (SLCs). Depending upon the composition, cubic, hexagonal and lamellar phases may be formed in such a quaternary mixture. ${ }^{12}$ These mesophases can be used as structure directing templates as they are stable over a wide range of $\mathrm{pH}$, temperature and composition. ${ }^{13}$ They are called 'swollen' liquid crystals because the aspects of the assembly can be varied by changing the composition. For example, diameter of the tubular assembly of surfactants in hexagonal mesophases can be varied over

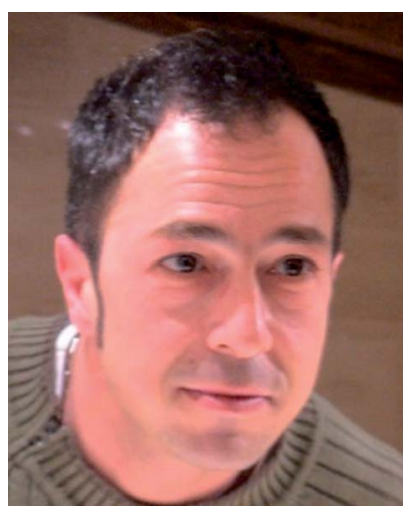

Dr. Samy Remita is a full Professor of Physical Chemistry and Head of the Department of Chemistry and Health \& Life Sciences at Conservatoire National des Arts et Métiers, CNAM, Paris, France. He is also an invited researcher at Laboratoire de Chimie Physique, LCP, UMR 8000, CNRS at Orsay, Paris-Saclay University. His research aims at exploiting radiation chemistry methodologies for synthesizing architecture-controlled organic and inorganic nanomaterials, tuning their physico-chemical properties and understanding their growth mechanism by the way of ultra-fast kinetics. a decade from $\sim 3 \mathrm{~nm}$ to $\sim 30 \mathrm{~nm}$ by changing the composition of the quaternary mixture. Even the distance between the tubes can be varied independently. ${ }^{14}$ Swollen liquid crystals (SLCs) can be formed from cationic, anionic and nonionic surfactants. They were used as soft templates in the synthesis of different nanostructures. In this review article, we will discuss briefly about the surfactants self-assembly, liquid crystals, swollen liquid crystals (SLCs) and their stability, different nanostructure synthesis using swollen liquid crystals (SLCs) etc. in much more detail.

\section{Surfactants and their self-assembly}

Surfactant self-assembly takes the advantage for synthesis of different nanostructured materials without nanostructures damage. Thus, the surfactants can self-assemble to form micelles above critical micelle concentration (CMC) and these micelles can be used as soft templates for nanomaterials synthesis. Thus, this approach for nanomaterials synthesis attracted much more attention in scientific community. Hence, it leads to the synthesis of different type of nanomaterials and more importantly, the nanomaterials size and shape can be tuned up using different concentration of surfactants. ${ }^{15}$ So, its important area of research work but before going to further detailed discussion, we need to discuss about critical packing parameter (CPP), Fontell scheme, phase diagram.

\section{Critical packing parameter (CPP)}

The critical packing parameter (CPP) is the most important parameter to determine the self-assembly behavior of amphiphilic molecules in micelles and was proposed by Israelachvili and co-workers. ${ }^{16,17}$

Estimating of this critical packing parameter (CPP) enables the determination of the surfactants molecular packing and formed preferred structure such as micelles, cylindrical micelles, bilayers, inverted micelles etc. as shown in Fig. 1 as determined by their respective critical packing parameter (CPP).

Fontell scheme for surfactant self-assembly of surfactants is also shown in Fig. 2, which clearly represents the normal and reverse mesophases formation.

Surface active agents, commonly known as surfactants, are the organic molecules that have hydrophilic polar head groups and long hydrophobic tail group(s). They have the tendency to get adsorbed at the interface between aqueous and oil medium. This results in the lowering of the free energy of phase boundary. Thus, they can reduce surface or interfacial tension. Surfactants exist as unimers below the critical micelle concentration (CMC) in water. However, they can self-assemble to form micelles above the critical micelle concentration (CMC). ${ }^{18,20} \mathrm{In}$ water, the hydrophobic tail groups of surfactant molecules are directed toward the interior of the core and the hydrophilic head groups are oriented toward the aqueous medium. Micelles can be treated as oil droplets in water and hence can solubilize oils inside the core to form oil-in-water emulsions, as shown in Fig. 3. Usually, micelles can be of spherical and cylindrical shapes depending on the shape of the surfactant molecules. 


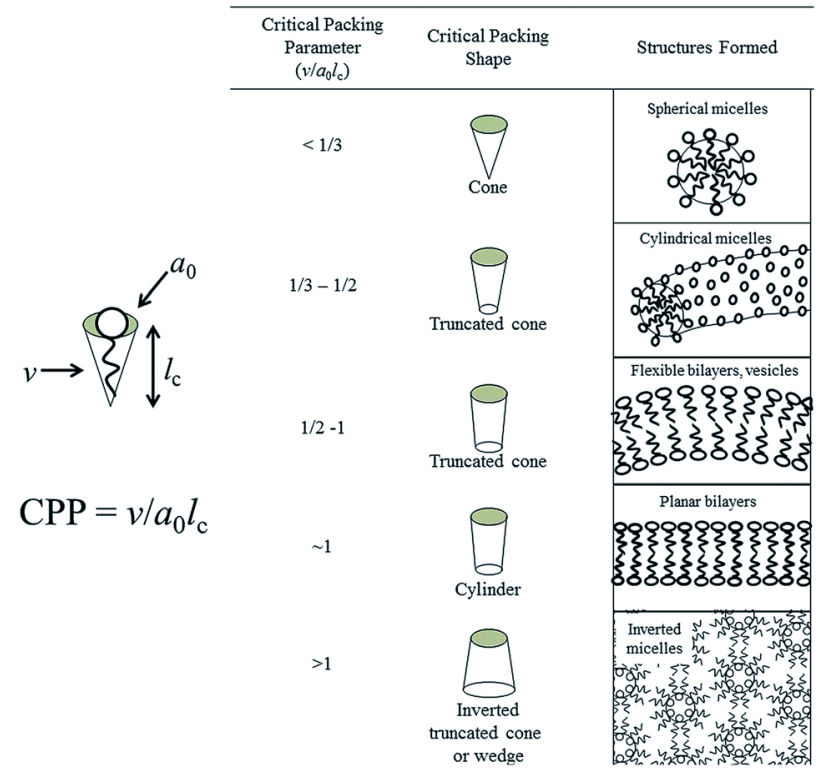

Fig. 1 Molecular shapes and critical packing parameter (CPP) of surfactants and lipids and the structures formed (here, $v=$ volume of hydrocarbon core, $a_{\mathrm{o}}=$ effective head group area, $l_{\mathrm{c}}=$ hydrocarbon chain length). Adapted with permission from ref. 18, copyright 2014, Royal Society of Chemistry.

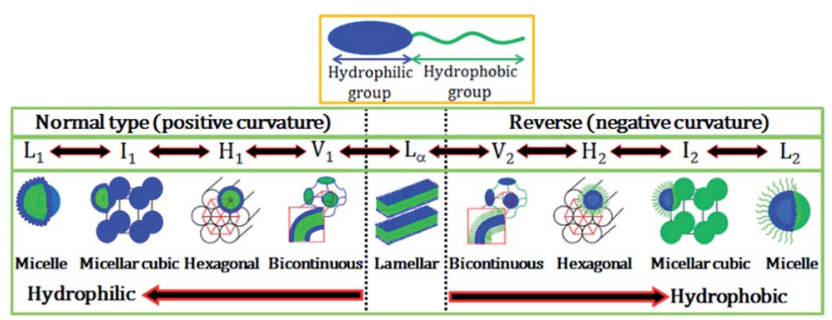

Fig. 2 Schematic representation of an amphiphilic molecule and normal and reverse type of surfactant self-assembled structures. $L_{1}, I_{1}$, $H_{1}, V_{1}$, and $L_{\alpha}$ represents normal micelle, micellar cubic phase, hexagonal phase, bicontinuous cubic phase, and lamellar phase, respectively. $V_{2}, I_{2}, H_{2}$, and $L_{2 \alpha}$ respectively represent reverse (inverted) phases. Adapted with permission from ref. 19, copyright 2014, Multidisciplinary Digital Publishing Institute.
Hydrophobic Chain

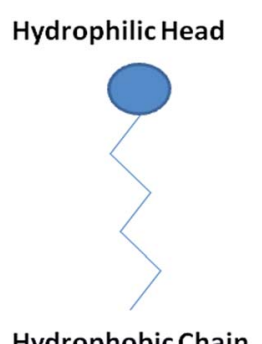

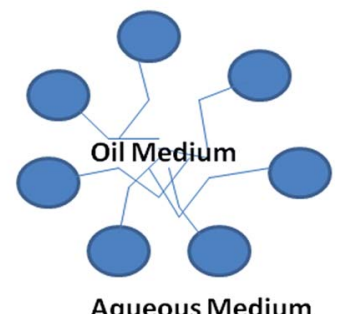

Micelles
Surfactant molecule

Fig. 3 Surfactant molecules and micelles formation above critical micelle concentration (CMC).

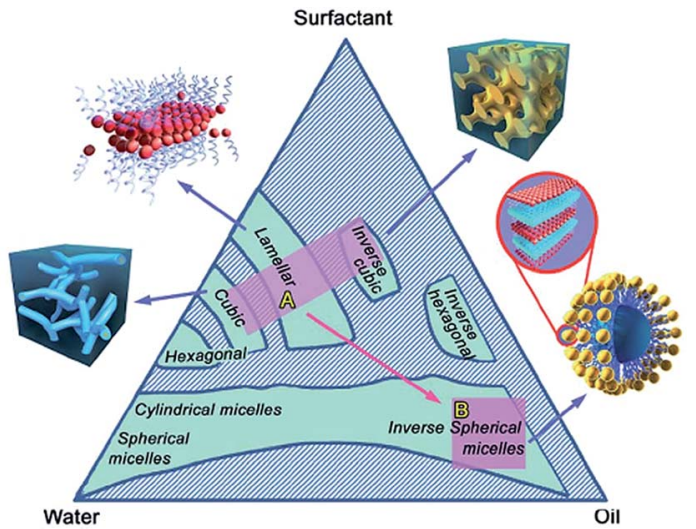

Fig. 4 A three component (water, oil and surfactant) phase diagram showing the formation of micelles and mesophases by the selfassembly of surfactants. Adapted with permission from ref. 24, copyright 2015, Royal Society of Chemistry.

However, micelles can be of less common shapes such as prolates, oblates, etc. At certain conditions, micelles can further self-assemble to form different types of mesophases such as hexagonal, cubic, lamellar and reverse hexagonal as shown in the phase diagram (Fig. 4). The micelles and the mesophases can be used as versatile templates for preparing different nanostructures such as of mesoporous and core-shell silica, nanofibers and rod-shaped mesoporous silica, $\mathrm{TiO}_{2}$ hollow structures $e t c .^{21-23}$

\section{Liquid crystals (LCs)}

Liquid crystals have gained much attention in the recent years due to their wide applications in different areas. Liquid crystals (LCs) is the state of matter that have the properties of both the liquid (molecular mobility and fluidity) and the crystalline (optical and electrical anisotropy) states. ${ }^{25}$ Liquid crystals (LCs) can also be defined as the mesophase that exhibits the properties of liquid i.e. they can flow like liquid and possess the long range orientational order. ${ }^{26}$ Liquid crystals (LCs) are mainly classified into two types: thermotropic liquid crystals and lyotropic liquid crystals (LLCs).

\subsection{Classifications of liquid crystals}

3.1.1. Thermotropic LCs. Thermotropic liquid crystals are formed by the action of heat and occurred in certain range of temperature.

3.1.1.1. Nematic phases. Nematic phase is the mostly fluid and widely used phase. Nematic phase has long range molecular positional ordering i.e. long axis of the molecule and tends to align in preferential direction, but has no positional ordering. ${ }^{27}$

3.1.1.2. Smectic phases. These types of mesophases are formed at lower temperature than nematic phases. The molecules are arranged in layers and exhibit some correlations in their positions in addition to the orientational ordering. 
3.1.2. Lyotropic liquid crystals (LLCs) or mesophases. Lyotropic liquid crystals (LLCs) exhibit the liquid crystalline behavior in a certain range of concentration. They usually have a liquid crystalline phase transition with temperature also. ${ }^{28,29}$ Interestingly, lyotropic liquid crystals (LLCs) can be used as templates for the synthesis of various nanostructures. ${ }^{30}$ Reversible photo-rheological lyotropic liquid crystals are also of great interest. These types of lyotropic liquid crystals (LLCs) are based on photoresponsive amphiphiles and they have photoswitchable rheological properties under UV and visible lights. ${ }^{31}$

Extensive research was carried out on lyotropic liquid crystals (LLCs) and received much attention recently. Lyotropic liquid crystals (LLCs) can be used for the synthesis of Bi, PdS nanoparticles. ${ }^{32}$ In lyotropic liquid crystals (LLCs) the main physical variation is concentration that determines the mesophase formation, whereas in thermotropic liquid crystals the main physical variation is temperature. ${ }^{33}$ Moreover, in lyotropic liquid crystals (LLCs), the main parameter is the concentration, which determine the phase transition also. ${ }^{34}$ Moreover, in thermotropic liquid crystals, it is already reported in the literature that the "blue phases" of liquid crystals exists both in narrow range and wide range of temperature. ${ }^{35}$ Also, the refractive index of the thermotropic liquid crystals were determined by temperature. ${ }^{36}$ Four-stranded aggregates of oligodeoxyguanylates and intermolecular hydrogen bonding interactions plays also role in formation of lyotropic liquid crystals and thermo liquid crystals respectively. ${ }^{37,38}$

Hexagonal, lamellar and cubic mesophases in lyotropic liquid crystals (LLCs) can be used as template for controlling the structure and morphology of the desired nanomaterial. In hexagonal mesophases, the long cylindrical micelles are arranged in hexagonal pattern. Each surfactant cylinder is surrounded by six other surfactant cylinders. ${ }^{\mathbf{1 4}}$

In lamellar mesophases, the surfactant molecules were arranged in bilayer fashion. The thickness of the bilayer is less than twice the surfactant molecular length. Lamellar mesophases can be used to synthesize different nanostructures. If the role of polar and nonpolar groups in surfactant chain has
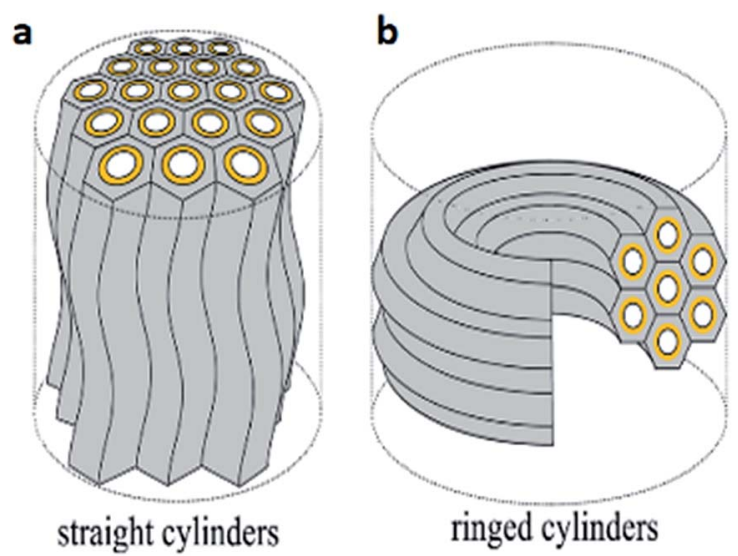

Fig. 5 (a) Straight cylinders with undulation and (b) ringed cylinders arrangements of hexagonal cylinders. Reprinted with permission from ref. 39. Copyright 2016 American Chemical Society. changed then it's called as reverse micelles and reverse hexagonal mesophase. Very recently, Toshihiko Oka and Noboru Ohta developed a method for the synthesis of two distinct domains of lyotropic liquid crystals (LLCs) with straight and ring cylinders in capillaries as shown in Fig. 5 and $6 .^{39}$

Reversible photorheological lyotropic liquid crystals (LLCs) were recently reported by S. Peng et $a l^{31}$ In their research, they showed that lyotropic liquid crystals (LLCs) based on azobenzene-containing surfactant (azo-surfactant) showed reversible photorheological behavior under UV and visible light as shown in Fig. 7. UV irradiation induced the trans to cis isomerization of the azo-surfactant, leading to the disruption of the ordered lyotropic liquid crystals (LLCs) phases and a dramatic rapid decrease in the viscosity and modulus.

\subsection{Applications of lyotropic liquid crystals (LLCs) in nanomaterials synthesis}

Lyotropic liquid crystals (LLCs) directed synthesis of nanomaterials are well known and widely reported in literature. Lyotropic liquid crystals (LLCs) (lamellar, hexagonal, cubic phases) can be used in the synthesis of zero dimensional, one dimensional, two dimensional, three dimensional nanomaterials. The lyotropic liquid crystals (LLCs) can also be used as template to synthesize nano sheets, nano particles, nano rods, porous nanostructures etc. Control over the geometry and interconnectivity of lyotropic liquid crystals (LLCs) nano channels allow us to control the size and shape of the nanostructures. ${ }^{40}$
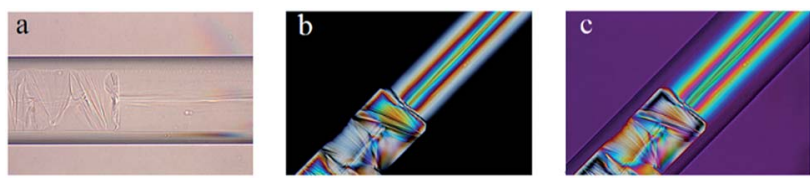

Fig. 6 Glyceryl monooleyl ether (GME) sample in a $0.2 \mathrm{~mm}$ diameter quartz capillary under polarized light. (a) Without an analyzer (a polarizer only) (b) and (c) Glyceryl monooleyl ether (GME) sample under polarized light when polarizer and analyzer are perpendicular to each other. Reprinted with permission from ref. 39. Copyright 2016 American Chemical Society.
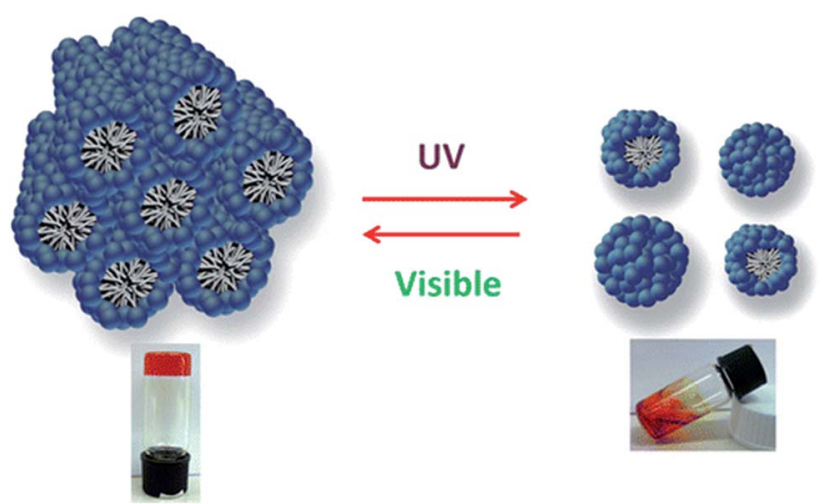

Fig. 7 Reversible behavior of photorheological lyotropic liquid crystals under UV and visible light. Reprinted with permission from ref. 31. Copyright 2014 American Chemical Society. 
Lamellar mesophase can be used as soft template confinement to synthesize gold nanoparticles and nanorods by the radiolytic reduction of metal salt. ${ }^{41}$ Nanoparticles of different diameter can be synthesized by tuning the thickness of water layer in the mesophase. In micellar solution above critical micelle concentration (CMC) gold nanorods of different aspect ratio can be synthesized by radiolysis. ${ }^{\mathbf{4 2}}$

The lyotropic liquid crystals (LLCs) can be used to synthesize zero dimensional, one dimensional and three dimensional nanostructures. We discuss the synthesis of these different nanostructures as below:

The lyotropic liquid crystals (LLCs) nano reactor approach can be used in nanoparticles synthesis. The reactants were confined in these lyotropic liquid crystals (LLCs) nano channels for nanostructures synthesis. ${ }^{32}$ In typical synthesis, $\mathrm{BiCl}_{3}$ and $\mathrm{CrCl}_{2}$ (a powerful reducing agent) as precursors salts were trapped inside the lyotropic liquid crystals (LLCs) separately in disposable syringes. After that, these two liquid crystals are connected and shear mixed, which leads to the synthesis of bismuth nanoparticles as shown in Fig. $8 .^{32}$

1-D nano structures are also nowadays an important area of research and lyotropic liquid crystals (LLCs) can be used to synthesize 1-D nano materials such as nanowires, nanorods and nanotubes etc. The $\mathrm{AgBr}$ and $\mathrm{SnO}_{2}$ micro wires were synthesized by mixing cetyltrimethyl ammonium bromide (CTAB) with oligoethylene alkyl ether/water semetic liquid crystals containing $\mathrm{AgNO}_{3}$ or $\mathrm{SnF}_{2} \cdot{ }^{43}$ Crystalline silver nanowire arrays with a high aspect ratio by electrodeposition from a reverse hexagonal liquid-crystalline phase containing one-dimensional aqueous channels were also synthesized by substituting the water phase with $0.1 \mathrm{M} \mathrm{AgNO}_{3}$ solution. ${ }^{44}$

2-D nano structured materials are also very much interesting both for academic as well as industrial research. The lyotropic liquid crystals (LLCs) template synthesis approach can be extended to synthesize 2-D nano structured materials. Hideya et al., reported the synthesis of Pt nano sheets based on new methodology using chemical reduction of platinum salt $\left(\mathrm{H}_{2} \mathrm{PtCl}_{6}\right)$ reducing with hydrazine in lyotropic liquid crystals (LLCs). The HR-TEM images of Pt-nano sheets synthesized using lyotropic liquid crystals (LLCs) were shown in Fig. 9.95

Ordered mesoporous silicates (MCM-41) and the mesoporous molecular sieves can also be synthesized after the removal of organic template by calcination. ${ }^{46}$
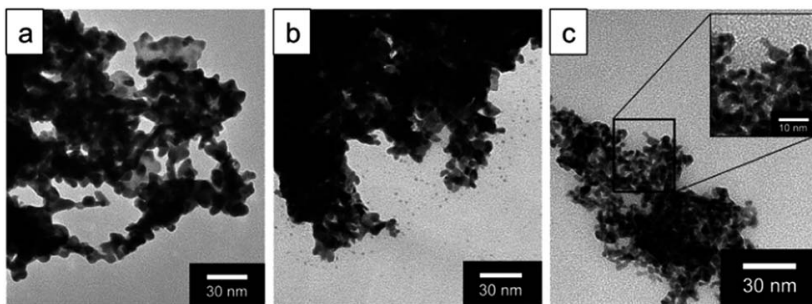

Fig. 8 TEM images of $\mathrm{Bi}$ nanoparticles produced by shear mixing of lyotropic liquid crystals (LLCS) (a) hexagonal phase (b) lamellar phase (c) inverse hexagonal phase. Reprinted with permission from ref. 32. Copyright 2004 American Chemical Society.

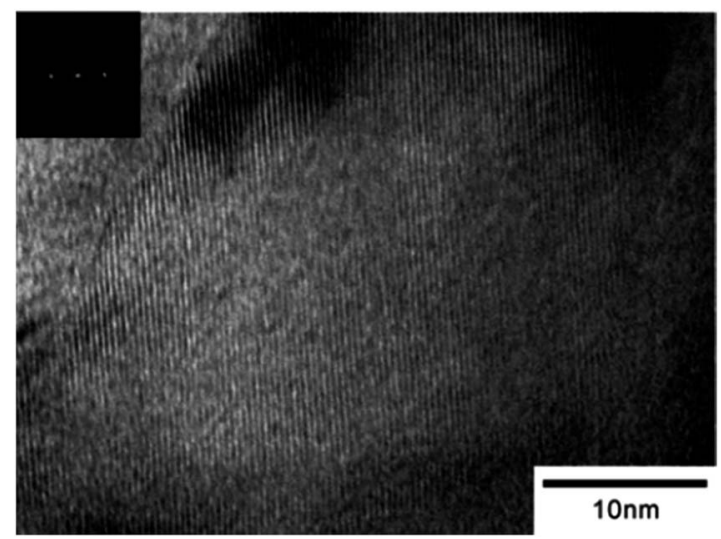

Fig. 9 HR-TEM image of Pt-nano sheets synthesized in lyotropic liquid crystals (LLCs). Reprinted with permission from ref. 45. Copyright 2005 American Chemical Society.

\section{Swollen liquid crystals (SLCs)}

Swollen liquid crystals (SLCs) are the class of lyotropic liquid crystals (LLCs) that are usually formed by a quaternary mixture of aqueous phase (brine or metallic salts etc.), oil (cyclohexane or aniline etc.), surfactant (cetyl trimethylammonium bromide (CTAB) or sodium dodecyl sulphate (SDS) etc.) and cosurfactant (1-pentanol). The interesting aspect of swollen liquid crystals (SLCs) is the tunability of various aspects of the mesophase assembly. For example, the diameter of the infinitely long surfactant cylinders in hexagonal mesophases can be varied from $\sim 3$ to $30 \mathrm{~nm}$ by varying the oil to water ratio (swelling the oil phase) and the concentration of salts in the aqueous solution as shown in Fig. $10 .^{47}$ Interestingly, even the distance between the surfactant cylinders can also be independently varied (swelling the aqueous phase).$^{47}$ Thus, the name 'swollen' liquid crystals is due to the possibility to swell the aqueous and oil phases.

Swollen liquid crystals (SLCs) are highly versatile as they can be formed by cationic, anionic and nonionic surfactants. Additionally, $\mathrm{NaCl}$ can be replaced with a large number of metal salts. Even, any water immiscible organic solvent can be used as oil phase. As the swollen liquid crystals (SLCs) can incorporate a large variety of organic and inorganic material inside and due

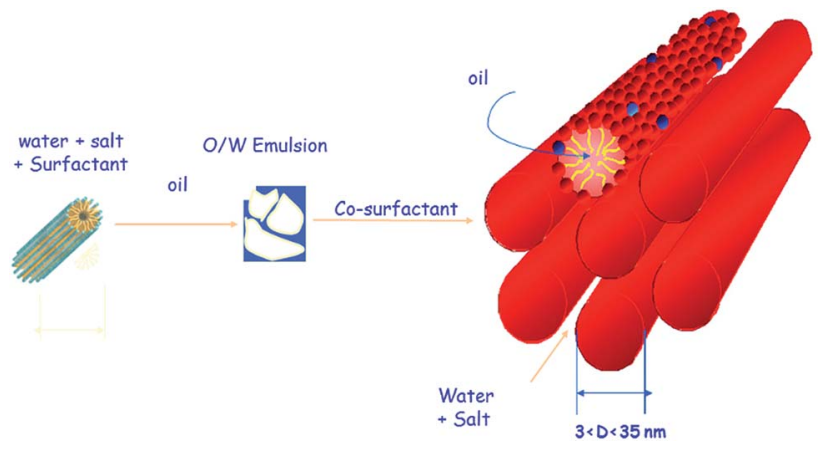

Fig. 10 Formation of swollen hexagonal mesophase from a four component system: water, surfactant, oil and cosurfactant. 
to their tolerance to variation in $\mathrm{pH}$ and temperature within certain ranges, they can be used as 'nanoreactors' ${ }^{48,49}$ Swollen liquid crystals (SLCs) can be of hexagonal, lamellar and cubic mesophases and hence they can be used as versatile templates for controlling the structure and morphology of variety of nanomaterials such as metals, polymers, metal oxides, etc. ${ }^{48}$ In hexagonal mesophases, the long cylindrical micelles are arranged in a hexagonal lattice. Each surfactant cylinder is surrounded by six other surfactant cylinders as shown in Fig. 10. The order of viscosity of the swollen liquid crystals (SLCs) varies in the following order: cubic > hexagonal > lamellar. It has also been demonstrated that the diameter of the non-polar cylinders in swollen liquid crystals (SLCs) can be correlated by following equation: ${ }^{50}$

$$
R=d_{\mathrm{c}}\left(\frac{\sqrt{3}}{2 \pi}\left(1-\phi_{\mathrm{p}}\right)\right)^{1 / 2}
$$

$R=$ radius of tubes, $d_{\mathrm{c}}=$ lattice parameter, $\phi_{\mathrm{p}}=$ volume fraction of polar medium.

When the ionic forces increase, accessible radii of cylinders, $R$, go from $1.5 \mathrm{~nm}$ (with pure water and without oil) to $17 \mathrm{~nm}$ (with brine $0.5 \mathrm{M}$ ), while the distance between adjacent tubes is kept small and nearly constant (between 2.1 and $2.9 \mathrm{~nm}$ ). ${ }^{50}$ Thus the diameter as well as the distance between the non-polar tubes in swollen liquid crystals (SLCs) can be controlled by the adjustment between cyclohexane and the ionic force of the aqueous salt solution.

\subsection{Characterization of swollen liquid crystals (SLCs)}

Swollen liquid crystals (SLCs) can be characterized using different characterization techniques such as small angle X-ray scattering (SAXS), polarizing optical microscopy (POM) and cryo-transmission electron microscopy (cryo-TEM).

4.1.1. Small angle X-ray scattering (SAXS). Small angle Xray scattering (SAXS) is a useful characterization tool used for inhomogeneous samples in nm-range and the scattering data is usually recorded at very low angles (typically $0.1-10^{\circ}$ ). Swollen liquid crystals (SLCs) can also be characterized using this technique. For example, the scattering pattern of a hexagonal mesophase consists of diffraction peaks whose positions are in the ratio $1:(3)^{1 / 2}: 2$, which corresponds to the (10), (11) and (20) diffraction planes. The first peak position, $q_{0}$, allows a direct determination of the hexagonal lattice parameter, $a$, according to $a=\left(2 / 3^{1 / 2}\right)\left(2 \pi / q_{0}\right) .{ }^{51}$ The hexagonal lattice parameter $(a)$ is the distance between the centers of two adjacent surfactant cylinders in the swollen liquid crystals (SLCs).

4.1.2. Polarizing optical microscopy (POM). Polarizing optical microscopy (POM) is the optical techniques in which the polarized light is used for imaging. Polarizing optical microscopy (POM) can also be used for characterizing swollen liquid crystals (SLCs) as does other liquid crystals (LCs). For polarizing optical microscopy (POM), a small amount of the swollen liquid crystals (SLCs) sample can be sandwiched between a clean glass slide and a cover slip. Vacuum grease can be applied to the edges of the cover slip to prevent the evaporation of the solvents and to protect the mesophases from collapsing. Typical textures
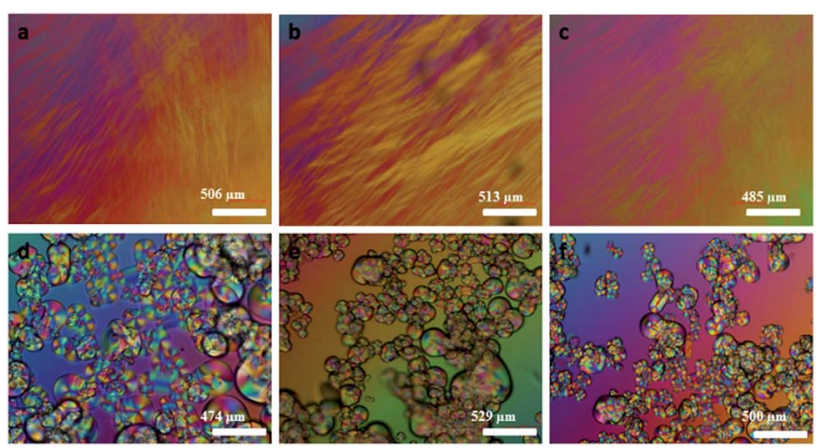

Fig. 11 Room temperature crossed polarizing optical microscopy (POM) optical images of $(a-c)$ fresh mesophases containing aniline, aniline hydrochloride and $\mathrm{H}_{2} \mathrm{PtCl}_{6} \cdot 6 \mathrm{H}_{2} \mathrm{O}$ respectively, (d-f) fan shaped focal conic texture in the same samples after 48 hours. Reproduced from ref. 52 with permission from Elsevier.

of some swollen liquid crystals (SLCs) are shown in Fig. 11. The hexagonal non-geometric texture can be clearly seen in freshly deposited samples $(\mathrm{a}-\mathrm{c})$. The focal conic texture of the hexagonal liquid crystals appear in the same samples, few hours after deposition on glass slides (d-f).

Moreover, metal nano clusters can be trapped inside the surfactants tubes of swollen liquid crystals (SLCs). The clusters can be heated to $55{ }^{\circ} \mathrm{C}$ and cooled to $20^{\circ} \mathrm{C}$ and it's observed that it showed the breakage and deformation of crystalline structure in polarizing optical microscopy (POM). ${ }^{53}$

4.1.3. Cryo-transmission electron microscopy (TEM). Cryotransmission electron microscopy (TEM) is usually used for imaging of biological samples and soft materials such as micelles and mesophases under cryo-cooled conditions. In cryo-transmission electron microscopy (TEM), the sample is usually deposited on the sample grid followed by blotting with filter paper and then rapidly plunged into liquid ethane. The microscopy is performed under liquid $\mathrm{N}_{2}$ temperature in a cryogenic environment. ${ }^{54}$ This microscopic technique is very much useful to study the liquid crystals. For example the cryo-transmission electron microscopy (TEM) images of hexagonal mesophases are shown in Fig. 12.
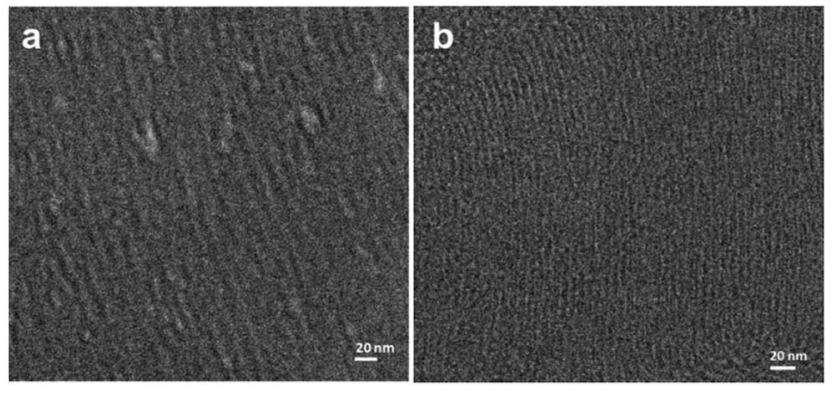

Fig. 12 Cryo-transmission electron microscopy (TEM) clearly shows the presence of an array of tubular rod-like micelles in the hexagonal swollen liquid crystals (SLCs) (a and b). Reproduced from ref. 54 with permission from the Centre National de la Recherche Scientifique (CNRS) and The Royal Society of Chemistry. 
4.2. Stability of swollen liquid crystals (SLCs) against change in chemical nature of the salts, inclusion of chemicals and materials, $\mathrm{pH}$ of the medium and temperature

A number of studies on the inclusion of various chemicals and materials in the aqueous and oil phases of swollen liquid crystals (SLCs) have been reported. ${ }^{\mathbf{4 8 , 5 5 , 5 6}}$ Very often these inclusions have been termed as 'doping' of the mesophases. The stability of swollen liquid crystals (SLCs) was not affected by the change of metal salts such as $\mathrm{NaF}, \mathrm{KCl}$ and $\mathrm{Na}_{2} \mathrm{SO}_{4}$ in place of $\mathrm{NaCl}^{.51}$ Even, the range of stability of swollen liquid crystals (SLCs) for brine was established in the concentration range of 01.1 to $0.5 \mathrm{M}^{57}$ Stable swollen liquid crystals (SLCs) were prepared by varying the $\mathrm{pH}$ from 1 to $11 .^{51}$ The oil phase of hexagonal swollen liquid crystals (SLCs) was doped with 1,4diphenylbutadiyne (DPB) which is a monomer and polymerization could be achieved within oil phases using benzoin methyl ether (BME) as a catalyst. ${ }^{51}$ Addition of amphiphilic copolymers such as amphiphilic polymer consisting of a polyethylene oxide (PEO) central block of molecular weight $5000 \mathrm{~g}$ $\mathrm{mol}^{-1}$ grafted at one extremity to a $\mathrm{C}_{18} \mathrm{H}_{37}$ aliphatic chain decorate at oil/water interface can increase the stability of surfactant hexagonal mesophases. ${ }^{47}$

Although, if the swelling ratio of oil/water $(\mathrm{O} / \mathrm{W})$ phase was varied even then the surfactants tubes remains in hexagonal pattern, swollen liquid crystals (SLCs) doped with $0.1 \mathrm{M} \mathrm{Pd} / \mathrm{Pt}$ salts with different $\mathrm{O} / \mathrm{W}$ ratio 1.5 to $4.5 .^{55}$

This hexagonal assembly has also been used for the synthesis of porous $\mathrm{Pt}$ nanostructures using $\gamma$-irradiation. ${ }^{58}$ Before and after $\gamma$-irradiation the hexagonal structure is preserved as shown below in Fig. 13, showing the stability of mesophase.

Moreover, even in bimetallic synthesis of metal nanostructures, the doping of the mesophases with metal salts as precursors does not affect the stability of hexagonal

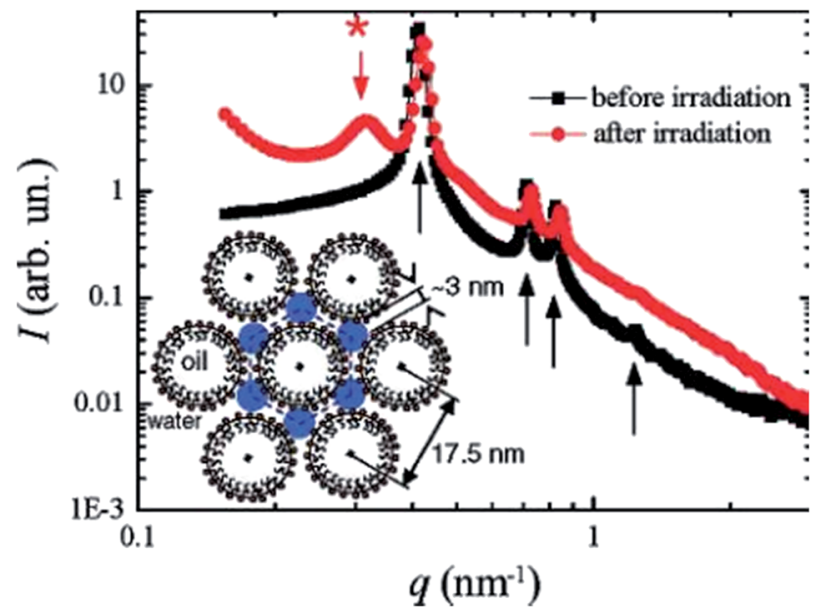

Fig. 13 Small angle X-ray scattering (SAXS) pattern of a Pt-doped swollen liquid crystals (SLCS), before (black squares) and after (red circles) $\gamma$-irradiation. Before irradiation the diffraction pattern is characteristic of a hexagonal phase and even after irradiation, the hexagonal structure is preserved. Reprinted with permission from ref. 58. Copyright 2007 American Chemical Society. arrangement of surfactant tubes as shown in Fig. 14. Small angle X-ray scattering (SAXS) experiments showed hexagonal symmetry in swollen liquid crystals (SLCs), with three Bragg peaks whose position are in the ratio $1: 3^{1 / 2}: 2$. The measured lattice parameter $d$ is $24.5 \mathrm{~nm}^{59}$

P. Fabre et al. explored the possibility of incorporating solid particles into lyotropic liquid crystals (LLCs) and concluded that it is possible to dope a lamellar mesophase with tiny solid particles without disturbing the initial smectic structure. ${ }^{60} \mathrm{C}$. Quilliet et al. studied the doping of the mesophase with nanoparticles suspended in cylcohexane. ${ }^{\mathbf{6 1 , 6 2}}$ The presence of such particles affected the lamellar structure and the lamellar zone shifted towards lower cosurfactant concentration with increase in particles. ${ }^{61,62}$ Interestingly, inclusion of ferrofluids in swollen liquid crystals (SLCs) by replacing the oil phase with ferrofluids was also studied and these swollen liquid crystals (SLCs) showed strong magnetic anisotropy under a magnetic field. ${ }^{\mathbf{6 3 , 6 4}}$ The behavior of the doped mesophase under magnetic field was studied using polarizing optical microscopy. It is also possible to trap magnetic particles up to a volume fraction of $2 \%$ inside the non-polar medium of the surfactant cylinders. The cylinder should be larger enough and the diameter of cylinder should be twice the diameter of trapped particle. ${ }^{57}$

Nanoparticles of $\mathrm{Pd}, \mathrm{Ru}, \mathrm{Ag}, \mathrm{Au}$ and $\mathrm{Cu}$ can be trapped inside the hexagonal mesophases. ${ }^{53}$ Cold welding of these trapped metal nanoparticles was explored as a method to prepare nanostructures, as the swollen liquid crystals (SLCs) can be heated up to $55^{\circ} \mathrm{C}$ and can be cooled down to $20^{\circ} \mathrm{C}$ to break and reform their crystalline behavior. ${ }^{53}$ The rheological behavior of oil swollen hexagonal liquid crystals was also investigated with small angle X-ray scattering (SAXS). The cylinders were found to be preferentially oriented along the flow and the hexagonal phase exhibits a polycrystalline texture at low shear regime. However, high shear has the effect of melting the long-range two-dimensional (2D) order of the cylinders, leading to a $2 \mathrm{D}$ liquid of cylinders strongly aligned along the flow. ${ }^{64}$

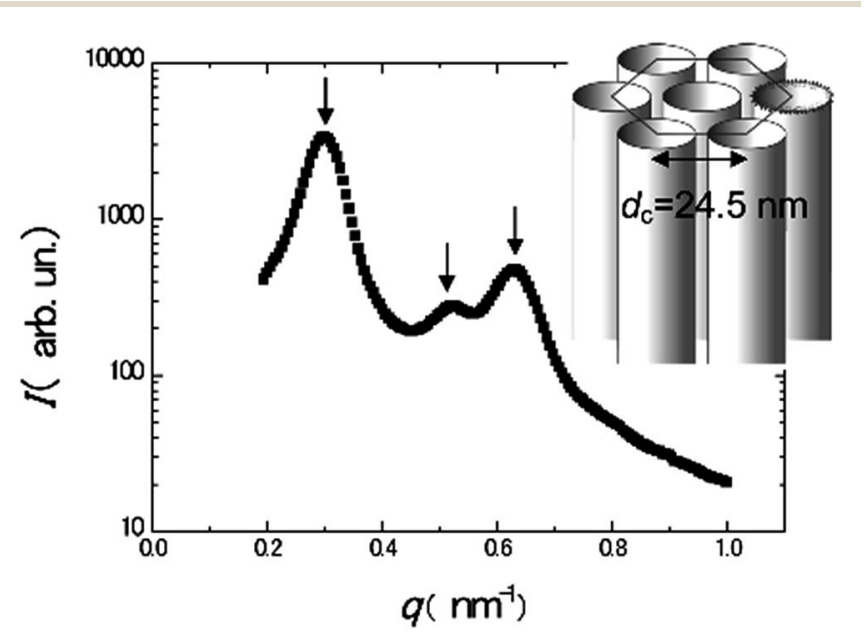

Fig. 14 Small angle X-ray scattering (SAXS) spectrum of the $\mathrm{Pd}-\mathrm{Au}$ doped hexagonal mesophase and scheme of the structure of the mesophase. The arrows point to the three main peaks. Reprinted with permission from ref. 59. Copyright 2009 American Chemical Society. 
A very important parameter, the co-surfactant determines the stability and phase transition of hexagonal pattern of swollen liquid crystals (SLCs). ${ }^{65}$ The stability and phase transition of different phases of swollen liquid crystals (SLCs) was determined using 1-pentanol as co-surfactant. The influence of 1-pentanol on the stability of swollen liquid crystals (SLCs) can be visualized directly and also using polarizing optical microscopy (POM) and small angle X-ray scattering (SAXS). ${ }^{65}$

\section{Use of swollen liquid crystals (SLCs) as soft templates}

Nanomaterials are interesting because of the novel properties that arise due to their nanometric size. These novel optical, electrical, electronic, mechanical and thermal properties can be tuned by varying the size as well as shape of nanomaterials. Hence, controlling the morphology of nanomaterials in the nanoscale is very important. Among the plethora of methods that are available for controlling the morphologies of nanomaterials, template assisted synthesis is more straightforward. This is mainly because of the possibility of rational design and synthesis of nanostructures by replicating the nanostructured molds (templates). Porous solids such as mesoporous silica, anodized aluminum oxide (AAO) and etched polycarbonate membranes that have ordered porosity can be used as templates. ${ }^{66}$ These are called 'hard' templates. On the other hand micelles and lyotropic liquid crystals (LLCs) also have ordered pores in the nanometer length scales and they can also be used as 'soft' templates. ${ }^{67}$ Both hard and soft templates are widely used for preparing various nanostructures. ${ }^{66,68}$ Soft templates are easy and convenient to use than the hard templates in certain aspects, especially when the pure nanomaterial has to be retrieved from the template. Removal of hard templates usually requires harsh conditions such as the use of highly corrosive chemicals, that may even rupture the prepared nanostructures. ${ }^{69}$ On the other hand soft templates can easily be removed by simple washing after the synthesis of nanostructures. $^{70}$ In the template assisted synthesis of nanomaterials, a precursor is first entrapped in the template. Subsequently, chemical reactions are initiated and the particle growth occurs while it is confined within the nano-chambers of the templates, thus leading to the formation of a replica. In hexagonal swollen liquid crystals (SLCs), the reaction can be performed in aqueous continuous medium which exists as a triangular space between three adjacent surfactant cylinders or in the oil medium within the surfactant cylinders.

Hexagonal mesophases were used widely to synthesize different noble metal nanostructures. ${ }^{55,71}$ Very high concentrations (up to $0.5 \mathrm{M}$ ) of metal salts can be entrapped in the swollen liquid crystals (SLCs) by using them as the ionic medium in the aqueous phase for the formation of swollen liquid crystals (SLCs). On the other hand, oil soluble metal salts can be dissolved in the oil phase also. ${ }^{70}$ The metal salts entrapped in the swollen liquid crystals (SLCs) can then be reduced to prepare the metal nanostructures. The reduction can be performed by exposing to reducing vapours and gases such as hydrazine, $\mathrm{CO}$ and $\mathrm{H}_{2} \cdot{ }^{70}$ Radiolytic reduction using $\gamma$-rays, electron beam and UV-visible light is more widely used as the swollen liquid crystals (SLCs) are transparent to these radiations. ${ }^{72,73}$ Radiolysis is powerful method to synthesize nanostructures and has the advantage over the chemical reduction method in terms of homogenous nucleation and overall growth. ${ }^{72}$

\subsection{Noble metal nanostructures}

A large number of noble metal nanostructures were synthesized using swollen liquid crystals (SLCs) as templates due to their potential applications of nanostructured noble metals in sensing and catalysis. ${ }^{74,75}$

Long and thin monocrystalline palladium (Pd) nanowires were synthesized using $\operatorname{Pd}_{2}(\mathrm{DBA})_{3}$ as oil soluble Pd-precursor. In a typical synthesis, cetyl trimethylammonium bromide (CTAB) or sodium dodecyl sulphate (SDS) or cetylpyridinium chloride (CPC) was used as surfactant, brine as aqueous phase, $\mathrm{Pd}_{2}(\mathrm{DBA})_{3}$ salt as metal precursor in toluene and 1-pentanol as cosurfactant. ${ }^{71}$ Hydrazine vapors were used to reduce the metal salts in all cases. It is interesting to note that with cetyl trimethylammonium bromide (CTAB) as the surfactant, Pd nanowires were formed while Pd nanoparticles were formed when sodium dodecyl sulphate (SDS) or cetylpyridinium chloride (CPC) were used a surfactants, as shown in Fig. 15.

Moreover, the morphology of Pd nanostructures could be tuned by using $\mathrm{CO}$ as a reducing agent in place of hydrazine as shown in Fig. 16. In a typical synthesis, the Pd salts such as $\mathrm{Pd}_{2}(\mathrm{DBA})_{3}$ or $\mathrm{Pd}(\mathrm{OAc})_{2}$ or $\mathrm{Pd}(\mathrm{acac})_{2}$ were dissolved in toluene and this solution was used to make the swollen liquid crystals (SLCs) with cetyl trimethylammonium bromide (CTAB) or sodium dodecyl sulphate (SDS). ${ }^{70} \mathrm{Pd}$ nanostructures were prepared by bubbling CO through the samples and extracted using 2-propanol. Surfactant plays a very important role in defining the final morphology of Pd nanostructures. When sodium dodecyl sulphate (SDS) was used as surfactant, then spherical Pd nanoparticles were formed, while Pd ultra-thin, uniform and hexagonal nanosheets were formed when cetyl trimethylammonium bromide (CTAB) was used as the surfactant as shown in Fig. 17. It might be due to the preferential adsorption of cetyl trimethylammonium bromide (CTAB) on
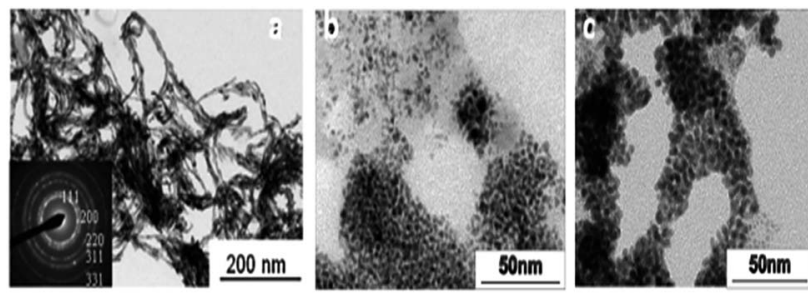

Fig. 15 TEM images of Pd nanostructures formed by hydrazine vapour treatment of a multicomponent hexagonal mesophase made of (a) cetyl trimethylammonium bromide (CTAB) (b) sodium dodecyl sulphate (SDS) and (c) cetylpyridinium chloride (CPC). Reproduced from ref. 71 with permission from the Centre National de la Recherche Scientifique (CNRS) and The Royal Society of Chemistry. 


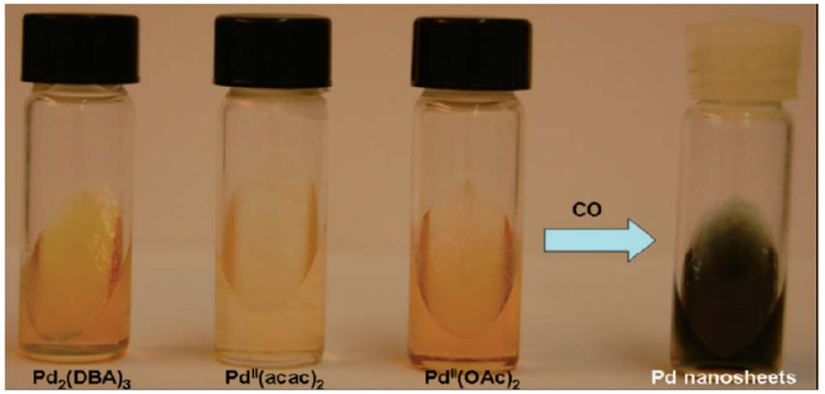

Fig. 16 Cetyl trimethylammonium bromide (CTAB)-based hexagonal mesophases containing Pd complexes $\left(1.5 \times 10^{-3} \mathrm{M}\right.$ in the oil phase) before and after the reaction with $\mathrm{CO}$. Reprinted with permission from ref. 63. Copyright 2007 American Chemical Society.

one of the facets of the Pd nuclei and thus facilitating the nanostructures to grow along other facets. ${ }^{71}$

Metal salts were dissolved in the aqueous medium to prepare mesophases doped with the metal ions that were reduced using various radiolytic and photolytic methods.

5.1.1. Palladium nanostructures. Pd nanowires of tens of nanometer length and uniform diameter were synthesized by using cetyl trimethylammonium bromide (CTAB) as surfactant and doping the mesophase with $\mathrm{Pd}\left(\mathrm{NH}_{3}\right)_{4} \mathrm{Cl}_{2}(0.1 \mathrm{M})$ as salt in the aqueous medium. The transparent and birefringent $\operatorname{Pd}\left(\mathrm{NH}_{3}\right)_{4} \mathrm{Cl}_{2}$ doped hexagonal mesophase was exposed to electron beam for radiolytic reduction to yield Pd nanowires. ${ }^{72}$ Swollen liquid crystals (SLCs) with different ratios of cosurfactant : surfactant ( $n_{\text {cosurfactant }}: n_{\text {surfactant }}$ between 0.78 to 0.91 ) were synthesized and irradiated using electron beam. From the TEM images (Fig. 18) it was concluded that the length of Pd nanowires increased with the increase in the amount of cosurfactant. The nanowires were formed due to the confinement effect that was provided by the mesophases. This was proved when only spherical Pd nanoparticles were formed in emulsions containing cetyl trimethylammonium bromide (CTAB), $0.1 \mathrm{M}$ $\operatorname{Pd}($ II) in water and cyclohexane (pentanol-free sample) or pentanol (cyclohexane-free sample) as shown in Fig. 19. ${ }^{72}$

Interestingly, the cetyl trimethylammonium bromide (CTAB) mesophases doped with $\mathrm{Pd}\left(\mathrm{NH}_{3}\right)_{4} \mathrm{Cl}_{2}$ as described above yielded
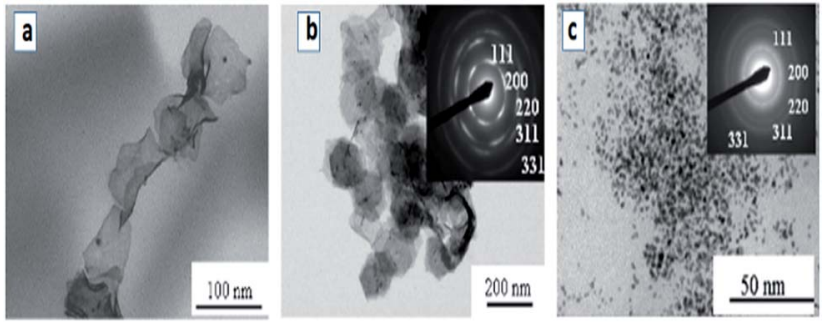

Fig. 17 TEM images of ( $a$ and $b)$ Pd nano sheets that were prepared by exposing the mesophases containing $\mathrm{Pd}$ complexes in the oil phase of water/toluene/cetyl trimethylammonium bromide (CTAB) to CO (c) TEM images of palladium nanoparticles prepared by the reaction of $\mathrm{CO}$ with $\mathrm{Pd}_{2}(\mathrm{DBA})_{3}$ in sodium dodecyl sulphate (SDS)-based hexagonal mesophase. Reprinted with permission from ref. 70. Copyright 2007 American Chemical Society.
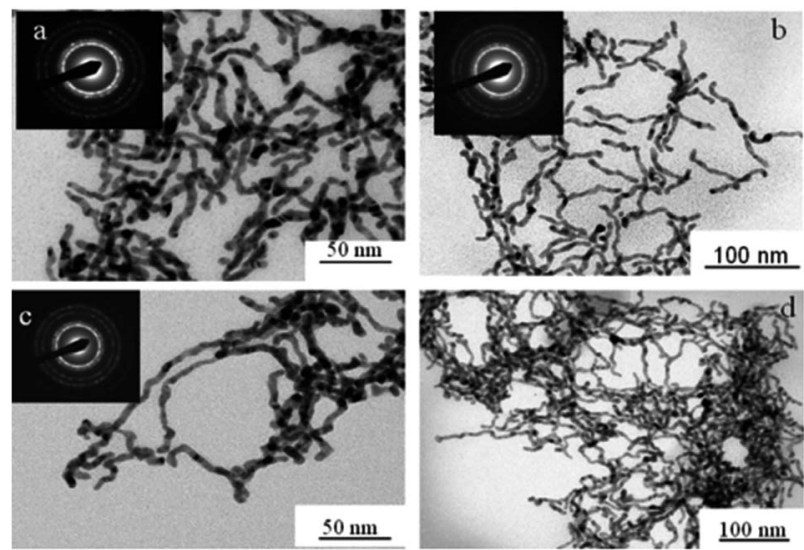

Fig. 18 TEM images of palladium nanowires formed in hexagonal mesophases using electron beam irradiation with different cosurfactant : surfactant ( $\left.n_{\text {cosurfactant }}: n_{\text {surfactant }}\right)$ molar ratio (a) 0.78 (b) 0.85 (c and d) 0. Reprinted with permission from ref. 72. Copyright 2009 American Chemical Society.

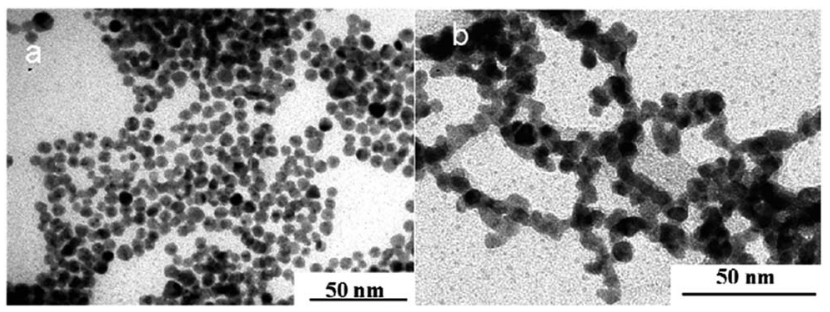

Fig. 19 TEM images of palladium nanoparticles obtained by irradiation using ternary system containing cetyl trimethylammonium bromide (CTAB), 0.1 M Pd in water and (a) cyclohexane (pentanol-free sample) (b) pentanol (cyclohexane-free sample). Reprinted with permission from ref. 72. Copyright 2009 American Chemical Society.

Pd-nanoballs when the mesophases were irradiated with $\gamma$ radiation instead of electron beam. ${ }^{76}$

5.1.2. Platinum nanostructures. Porous platinum nanostructures are highly useful in catalysis and swollen liquid crystals (SLCs) can be used to synthesize porous metal nanostructures. Platinum nanonets (PtNNs) and platinum nanoballs (PtNBs) as shown in Fig. 20 can be synthesized in swollen liquid crystals (SLCs) by using radiolytic methods. Swollen liquid crystals (SLCs) with cetyl trimethylammonium bromide (CTAB) was doped with $\mathrm{Pt}\left(\mathrm{NH}_{3}\right)_{4} \mathrm{Cl}_{2}$ as metal precursor salt and irradiation dose of $40 \mathrm{kGy}$ was used for making platinum nanonets (PtNNs), whereas $80 \mathrm{kGy}$ was used for platinum nanoballs (PtNBs). ${ }^{73}$ The synthesized nanostructures showed very good catalytic activity for the reduction of $p$-nitrophenol. Pt fractals can be synthesized in lamellar liquids crystals and porous platinum nanoballs in the hexagonal mesophase using $\gamma$-rays. ${ }^{58}$

Porous Pt nanoballs made of connecting wires as shown in Fig. 21 can be synthesized using radiolysis in water containing phase of swollen liquid crystals (SLCs). Mesophase was prepared using cetyl trimethylammonium bromide (CTAB) as surfactant, tetraammineplatinum(II) $\mathrm{Pt}\left(\mathrm{NH}_{3}\right)_{4} \mathrm{Cl}_{2}$ as metal salted medium and sample were exposed to $\gamma$-irradiation. 

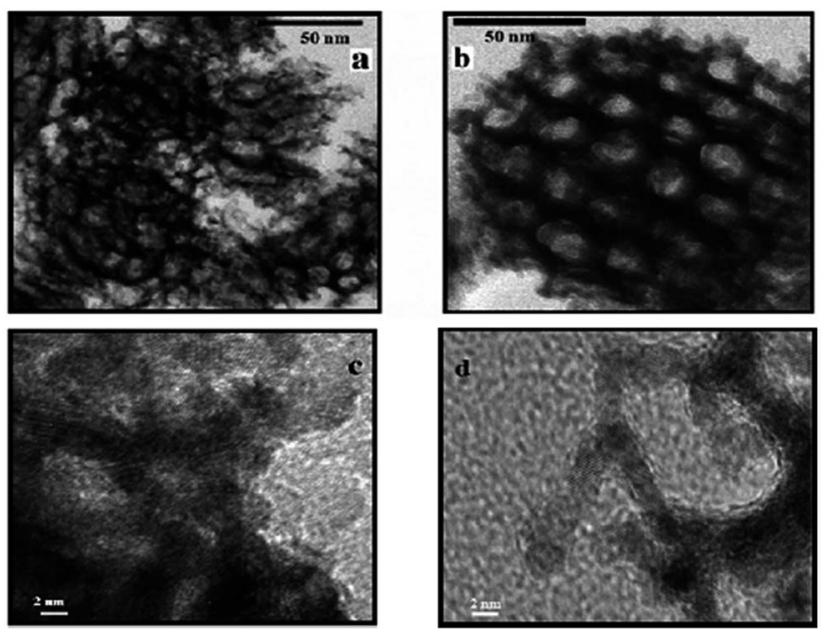

Fig. 20 TEM and HRTEM images of (a and c) platinum nanonets (PtNNs) and ( $b$ and $d$ ) platinum nanoballs (PtNBs) synthesized in swollen liquid crystals (SLCs). Reprinted with permission from ref. 73. Copyright 2013 American Chemical Society.
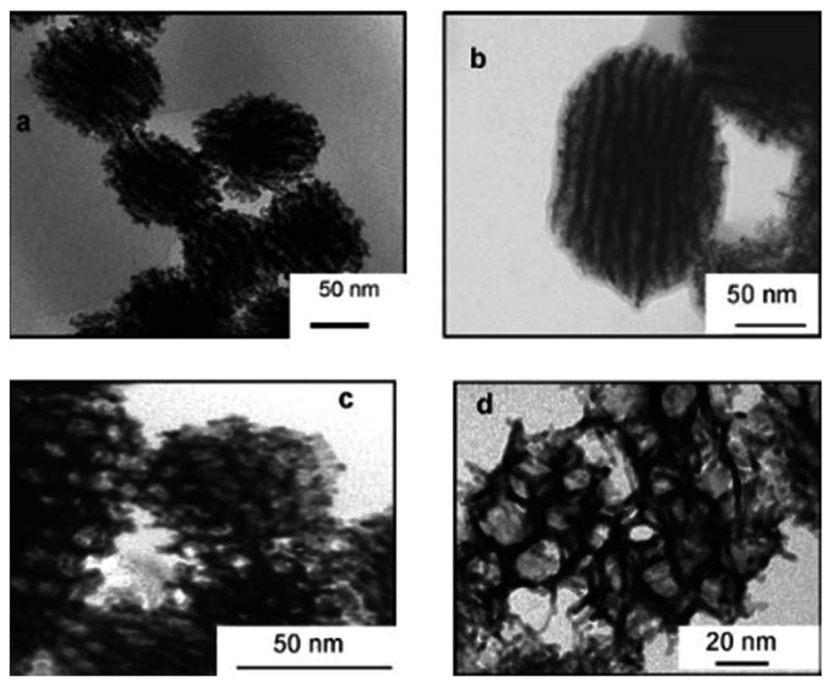

Fig. 21 TEM images of porous platinum nanoballs made by connected nanowires and formed after complete reduction (16 $\mathrm{h} \gamma$-irradiation) dose rate $3 \mathrm{kGy} \mathrm{h}^{-1}$. Reprinted with permission from ref. 58. Copyright 2007 American Chemical Society.

\subsection{Bimetallic nanostructures}

Swollen liquid crystals (SLCs) can be doped with more than one metal salt and then chemical or radiolytic methods can be used for making bi-metallic nanostructures. Mesophases were doped with Pd and Pt salts by completely or partially replacing $\mathrm{NaCl}$ in aqueous medium and cetyl trimethylammonium bromide (CTAB) or cetyltrimethylammonium chloride (CTAC) or cetylpyridinium bromide (CPBr) were used as surfactants. These mesophases were then exposed to $\gamma$-radiations (dose rate $1.85 \mathrm{kGy} \mathrm{h}^{-1}$ ) and irradiation time $5 \mathrm{~h}$ (9.25 kGy), $12 \mathrm{~h}$ (22.2 kGy), $24 \mathrm{~h}$ (44.4 kGy) and $48 \mathrm{~h}$ (88.8 kGy) to yield bi-metallic Pt-Pd nanostructures..$^{55}$

Interestingly core-shell nanostructures were formed when mesophases simultaneously doped with Pd and Au salts were exposed to $\gamma$-radiation $\left({ }^{60} \mathrm{Co}\right.$ panoramic source: dose rate 2.2 kGy $\mathrm{h}^{-1}$ ) and dose $22 \mathrm{kGy}$ and $9 \mathrm{kGy} .{ }^{59}$ Cetyl trimethylammonium bromide (CTAB) was used as surfactant, cyclohexane as the oil phase and tetraamminepalladium(II) $\mathrm{Pd}\left(\mathrm{NH}_{3}\right)_{4} \mathrm{Cl}_{2}$ and ethylenediamine gold(III) $\left[\mathrm{Au}(\mathrm{en})_{2}\right] \mathrm{Cl}_{3}$ were used as metal salts. ${ }^{59}$

\subsection{Oxide nanostructures}

Zirconia needles can also be synthesized using swollen liquid crystals (SLCs) in the aqueous medium after thermal treatment. ${ }^{77}$ Swollen liquid crystals (SLCs) formed of cetylpyridinium chloride (CTPCl) doped with zirconium sulfate colloids (ZSC) were used to synthesize the zirconia needles having length up to $2 \mathrm{~cm}^{78}$

Zirconia micro needles as shown in Fig. 22 and 23 can be synthesized in swollen liquid crystals (SLCs) by mixing the proper ratio of aqueous solution of zirconium colloids (precursor), cetylpyridinium chloride (surfactant), cyclohexane (swelling agent) and 1-pentanol as co-surfactant. The morphology of the $\mathrm{Zr}$ needles was controlled by swollen liquid crystals (SLCs) templating. ${ }^{71}$

\subsection{Polymer nanostructures and their nanocomposites}

SLCs can be used as versatile soft template for the synthesis of different polymer nanostructures. Different nanostuctures like open vesicles and spindles as shown in Fig. 24 of poly(3,4ethylenedioxythiophene) (PEDOT) were synthesized using swollen liquid crystals (SLCs). ${ }^{54}$ 3,4-Ethylenedioxythiophene

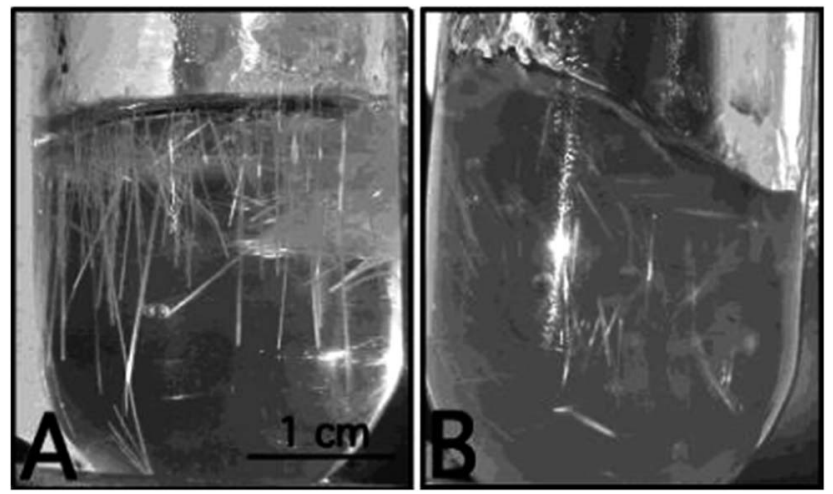

Fig. 22 Photographs (A and B) of the reaction vessel containing $\mathrm{Zr}$ needles. Reprinted with permission from ref. 78. Copyright 2004 American Chemical Society.
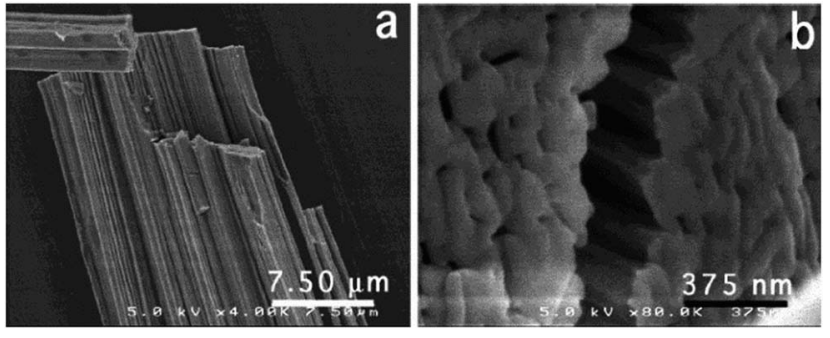

Fig. 23 SEM images of $\mathrm{Zr}$ needles (a) and close view of cross section (b). Reprinted with permission from ref. 78. Copyright 2004 American Chemical Society. 

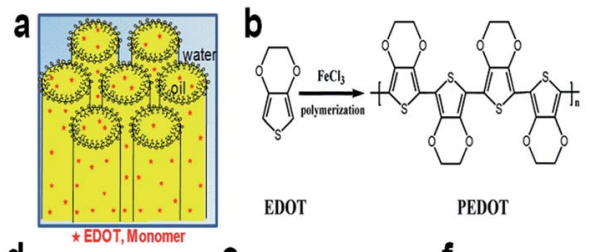

EDOT

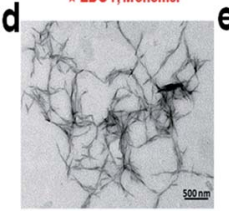

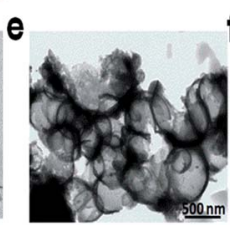

PEDOT

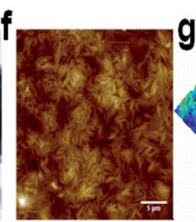

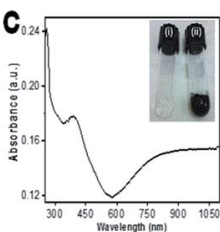

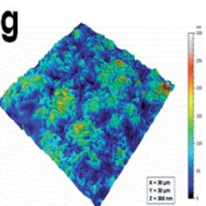

Fig. 24 (a) Hexagonal mesophases doped with 3,4-ethylenedioxythiophene (EDOT) monomer. (b) Schematic representation of chemical oxidative polymerization of 3,4-ethylenedioxythiophene (EDOT) using $\mathrm{FeCl}_{3}$ as chemical oxidant. (c) Absorption spectrum of ethanolic solution of poly(3,4-ethylenedioxythiophene) (PEDOT) nanospindles. Inset: photograph of doped swollen hexagonal phases synthesized in presence of $0.3 \mathrm{M} \mathrm{NaCl}$. (i) Transparent gel before polymerization and (ii) dark blue gel after polymerization by $\mathrm{FeCl}_{3}$. (d) Transmission electron micrograph (TEM) of poly(3,4-ethylenedioxythiophene) (PEDOT) nanospindles synthesized in presence of $0.3 \mathrm{M} \mathrm{NaCl}$. (e) TEM image of poly(3,4-ethylenedioxythiophene) (PEDOT) vesicles synthesized in presence of $0.1 \mathrm{M} \mathrm{NaCl}$. (f) Typical AFM topographic image of poly(3,4-ethylenedioxythiophene) (PEDOT) nanospindles extracted from mesophases and deposited onto ZnSe substrate. (g) The corresponding 3D AFM image of poly(3,4-ethylenedioxythiophene) (PEDOT) nanostructures. Reprinted by permission from Macmillan Publishers Ltd: Scientific Reports, ${ }^{79}$ copyright (2015).

(EDOT) monomer was entrapped in the oil phase whereas $\mathrm{FeCl}_{3}$ (oxidant) was entrapped in the aqueous phase.

Polypyrrole (PPy) nanoparticles were prepared using lamellar mesophases by the reaction between mesophase (A) containing pyrrole and mesophase (B) containing ammonium peroxydisulfate. ${ }^{80}$ The mesophases were poured over each other and the reaction occurred by natural diffusion leading to the formation of polypyrrole (PPy) nanoparticles as shown in Fig. 25. Spherical nanoparticles of polypyrrole were formed and these were deposited in the form of a film using spin coating and then used as substrate for the deposition of $\mathrm{ZnO}$ nanostructures. ${ }^{\mathbf{8 0}}$
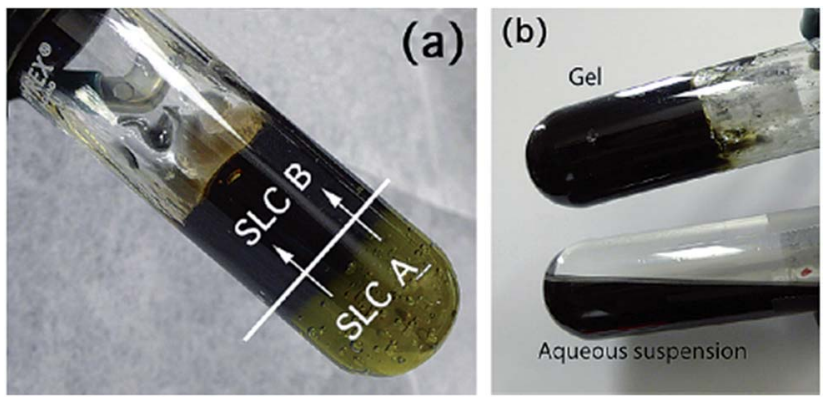

Fig. 25 Synthesis of polypyrrole (PPy) nanoparticles in lamellar swollen liquid crystals (a) using swollen liquid crystals (SLCs) containing the pyrrole (A) and the swollen liquid crystals (SLCS) containing ammonium peroxydisulfate (B); (b) product at end of reaction (top) and polypyrrole (PPy) nanoparticles obtained after extraction (bottom). Reprinted with permission from ref. 80. Copyright 2010 American Chemical Society.
Different polyaniline nanostructures (PANI-NS) can also be synthesized using aniline or aniline hydrochloride monomer trapped in oil phase or in aqueous phase respectively of swollen liquid crystals (SLCs). The trapped monomer were oxidized using ammonium persulphate as oxidant under different mixing (M) and diffusion (D) conditions. Different ways of polymerization lead to the formation of spherical and one dimensional polyaniline nanostructures (PANI-NS) as shown in Fig. 26 and $27^{77,81}$

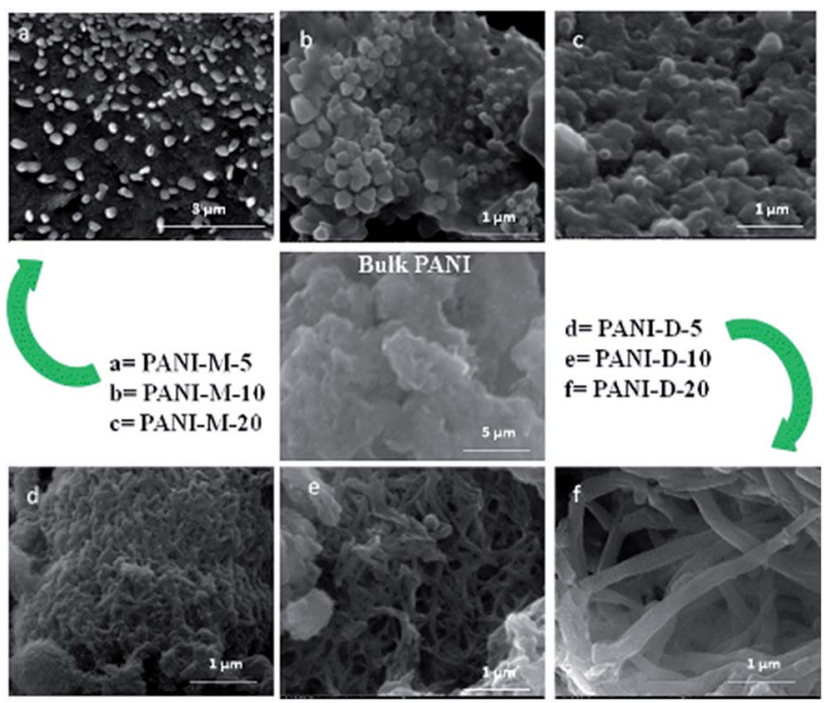

Fig. 26 FESEM images of bulk-polyaniline (PANI) (prepared without swollen liquid crystals (SLCs)) and nanostructured-PANI samples $M=$ mixed, $\mathrm{D}=$ diffusion conditions, 5, 10, 20 is the aniline/cyclohexane (volume/volume ratio) in oil phase of swollen liquid crystals (SLCs). ${ }^{77}$ Reproduced with permission from Wiley- $\mathrm{VCH}$.
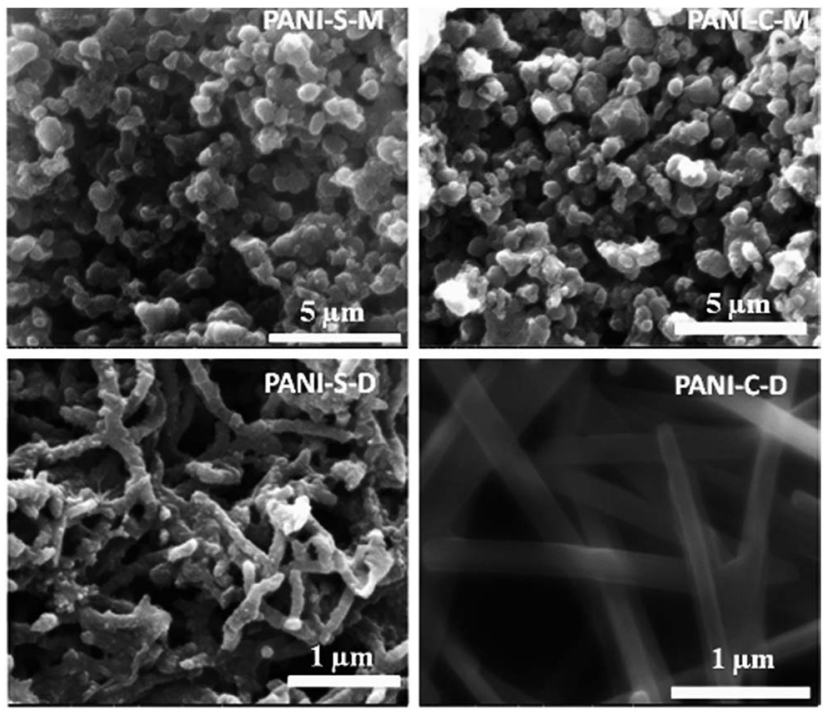

Fig. 27 FESEM images of polyaniline nanostructures (PANI-NS) prepared under different conditions using aniline hydrochloride monomer in aqueous phase of swollen liquid crystals (SLCS) [C = cetyl trimethylammonium bromide (CTAB), $\mathrm{S}=$ sodium dodecyl sulphate (SDS) as surfactants]. Reproduced from ref. 81 with permission from Elsevier. 
The possible proposed mechanism for different polyaniline nanostructures (PANI-NS) formations is given Fig. 28. It is demonstrated that under mixed conditions, 0-D polyaniline (PANI) nanostructures were formed due to fast rate of polymerization and on the other hand, under diffusion conditions, 1-D polyaniline (PANI) nanostructures were formed due to slow rate of polymerization.

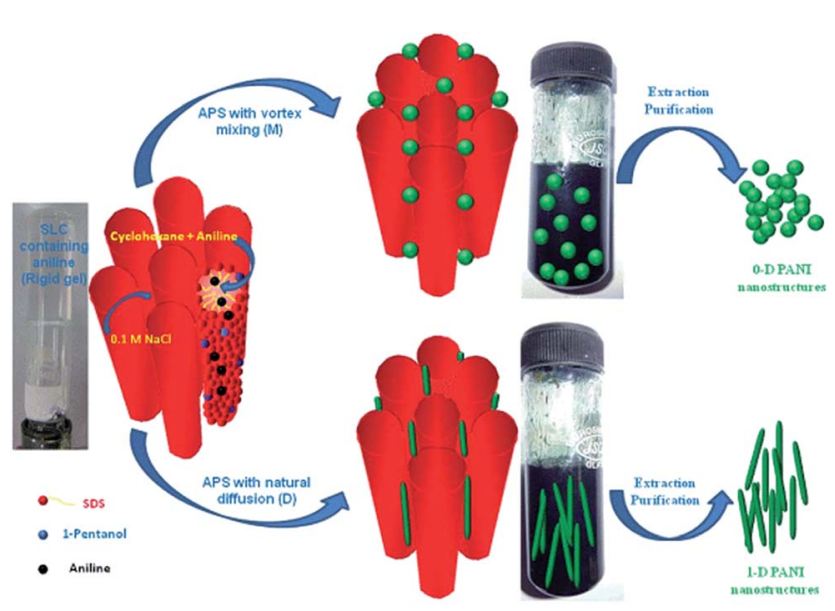

Fig. 28 Proposed mechanism for the formation of $0-D$ and 1-D polyaniline (PANI) nanostructures in swollen liquid crystals (SLCs). ${ }^{77}$ Reproduced with permission from Wiley- $\mathrm{VCH}$.
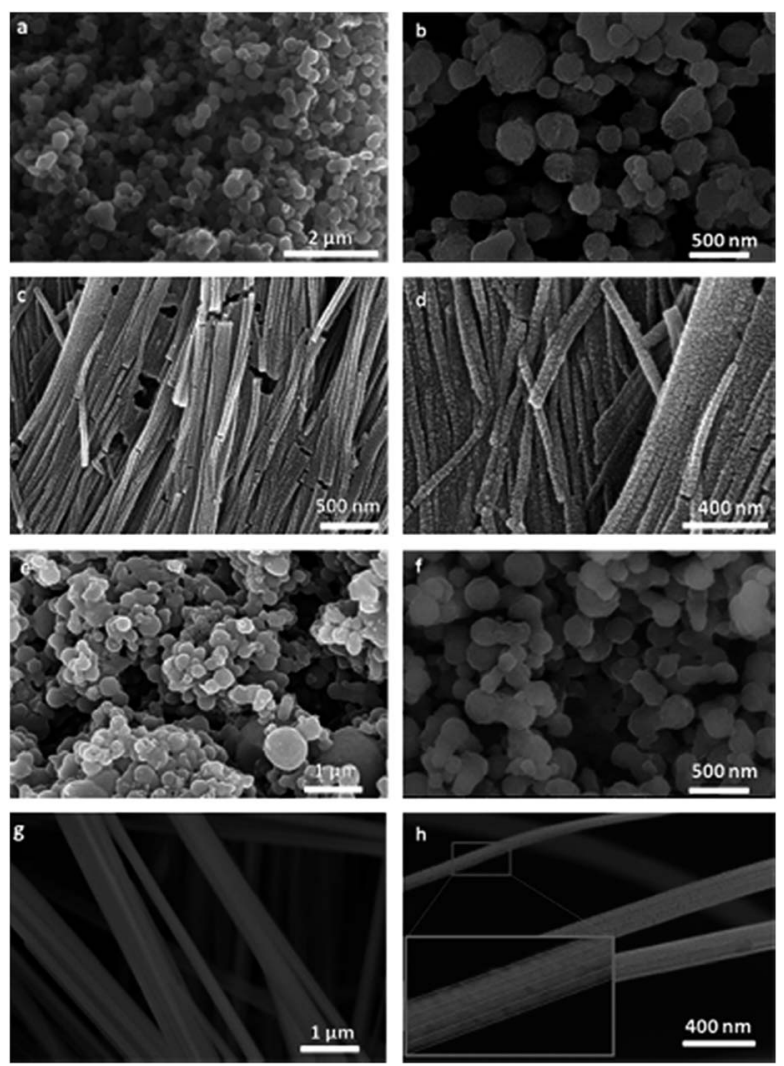

Fig. 29 FESEM images of PANI-Pt nanocomposites (a and b) AN-Pt$\mathrm{M}$, (c and d) AN-Pt-D (e and f) AN. HCl-Pt-M and ( $g$ and $h$ ) AN. HClPt-D. Reproduced from ref. 52 with permission from Elsevier.
The aniline (AN) or aniline hydrochloride $(\mathrm{AN} \cdot \mathrm{HCl})$ monomer in oil phase or aqueous phase respectively of swollen liquid crystals (SLCs) can also be polymerized using hydrogen hexachloroplatinate $\left(\mathrm{H}_{2} \mathrm{PtCl}_{6} \cdot 6 \mathrm{H}_{2} \mathrm{O}\right)$ metal salt as oxidizing agent for
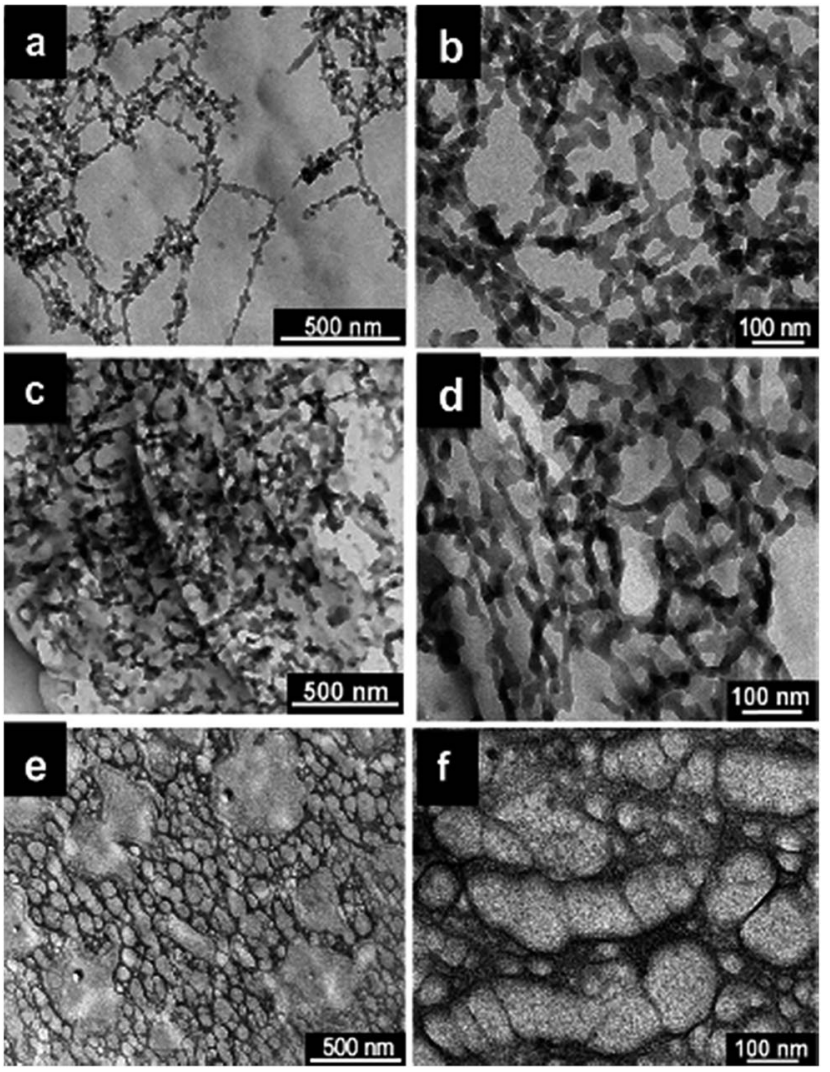

Fig. 30 TEM images of poly(diphenylbutadyine) (PDPB) nanostructures prepared using UV irritation in mesophases with ( $a$ and b) $\phi$ (swelling ratio), volume ratio of oil over water $(\mathrm{v} / \mathrm{v})=2.21$ and $C_{\mathrm{s}}$ (total salt concentration) $=0.3 \mathrm{M} \mathrm{NaCl}$, (c and d) $\phi=0.98$ and $C_{\mathrm{s}}=0.1 \mathrm{M}$ $\mathrm{NaCl}$, (e and f) $\phi=0.72$ and $C_{\mathrm{s}}=0 \mathrm{M} \mathrm{NaCl}$. Reproduced from ref. 82 with permission from the Centre National de la Recherche Scientifique (CNRS) and The Royal Society of Chemistry.

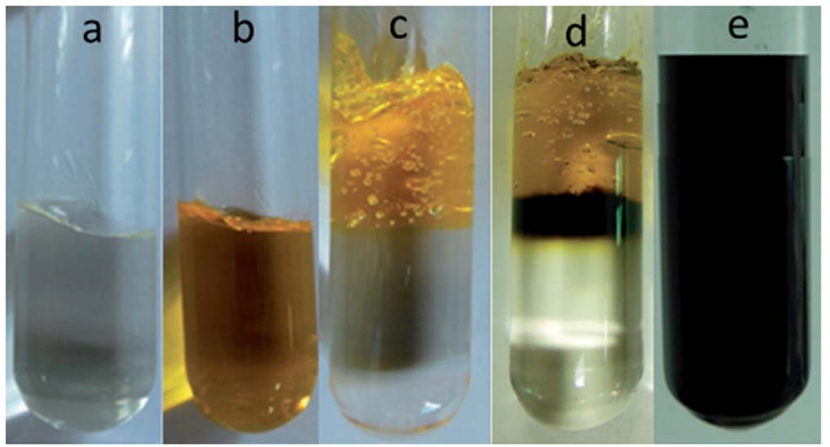

Fig. 31 Photographs of (a) mesophase containing aniline, (b) mesophase containing gold chloride, (c) mesophases at the time of mixing, (d) mesophases after $1 \mathrm{~h}$ reaction and (e) mesophases after $72 \mathrm{~h}$ showing the completion of reaction. Reproduced from ref. 83 with permission from the Centre National de la Recherche Scientifique (CNRS) and The Royal Society of Chemistry. 


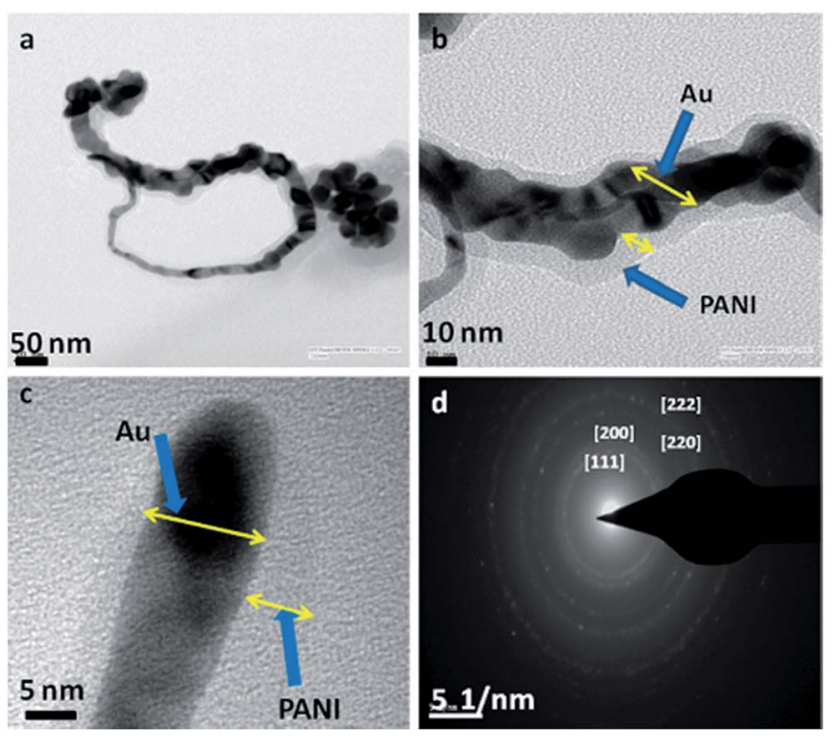

Fig. 32 TEM images of gold $_{\text {core }}-$ polyaniline shell $_{\text {composite nanowires }}$ synthesized using swollen liquid crystals (SLCs) (a) long nanowire and some nanoparticles, (b) high resolution image of portion of (a) where the polyaniline (PANI) shell is clearly visible, (c) end of a nanowire and (d) the selected area electron diffraction (SAED) pattern. Reproduced from ref. 83 with permission from the Centre National de la Recherche Scientifique (CNRS) and The Royal Society of Chemistry.

polyaniline (PANI)-Pt nanocomposites synthesis..$^{52}$ The synthesized polyaniline (PANI)-Pt nanostructures were characterized using SEM as shown in Fig. 29 and have spherical or wire like morphology that depends upon the way of mixing (M) or diffusion (D) of the monomer with metal salt as oxidant, both confined in swollen liquid crystals (SLCs).

The diameter of the synthesized polymer nanostructures can also be controlled by using monomer doped swollen liquid crystals (SLCs) nanotubes with different swelling ratio (oil/water ratio) as shown in Fig. 30. Cyclohexane containing 1,4-diphenylbutadyine as monomer and benzoin methyl ether (BME) as catalyst was trapped in oil phase of swollen liquid crystals (SLCs) and polymerized using UV or $\gamma$-rays at different swelling ratios (in radiolytic synthesis no initiator was used). The diameter of the poly(diphenylbutadyine) (PDPB) nanostructures can be varied from 5 to $25 \mathrm{~nm}$ and is directly determined by the diameter of the oil tube of the doped mesophases. ${ }^{82}$
Gold $_{\text {core }}$-polyaniline shell $_{\text {composite nanowires with unique }}$ morphology were also synthesized using swollen liquid crystals (SLCs). ${ }^{83}$ The aniline monomer containing mesophase was poured over gold chloride containing mesophase and the reaction was allowed to start under slow diffusion as shown in Fig. 31.

Gold $_{\text {core-polyaniline }}$ shell composite nanowires with unique morphology with polyaniline masked gold nanowires were synthesized as shown in Fig. 32.

\section{Application of the nanostructured materials synthesized using swollen liquid crystals (SLCs)}

The different nanostructured materials synthesized using swollen liquid crystals (SLCs) find it better application in different areas such as in sensing, electrocatalysis, photocatalysis, etc. as discussed in detail below.

\subsection{Alcohol electro oxidation}

Pd nanoplates synthesized using swollen liquid crystals (SLCs) in solution by slow reduction via radiolysis supported with poly
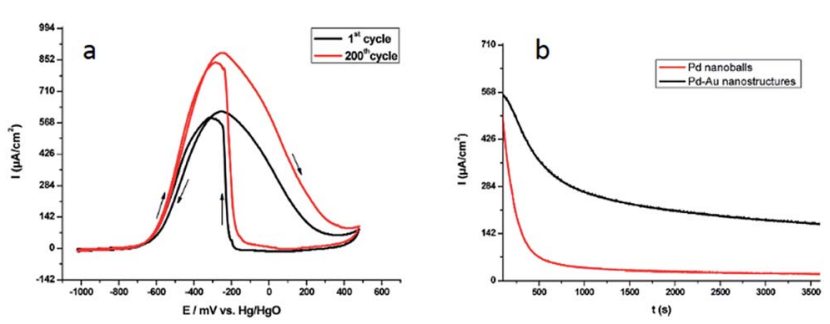

Fig. 33 (a) Superposition of the first (black solid line curve) and the $200^{\text {th }}$ (red solid line curve) cyclic voltammetric runs associated with the electrocatalytic oxidation of $1 \mathrm{M} \mathrm{EtOH}$ in $1 \mathrm{M} \mathrm{KOH}$ with continuous cycling of the electrode potential. The working electrode was a glassy carbon disk modified with the bimetallic $\mathrm{Pd}-\mathrm{Au}_{\text {meso }}$ nanostructures synthesized in the mesophase. The reference electrode was an $\mathrm{Hg} / \mathrm{HgO}(1 \mathrm{M} \mathrm{KOH})$ electrode. The scan rate was $50 \mathrm{mV} \mathrm{s}^{-1}$ (b) chronoamperometric curves for ethanol electrooxidation at $-0.3 \vee v s$. $\mathrm{Hg} / \mathrm{HgO}$ on a glassy carbon electrode modified with bimetallic $\mathrm{Pd}-\mathrm{Au}_{\text {meso }}$ nanostructures synthesized in a hexagonal mesophase (black curve) or Pd nanoballs (red curve). The solution was $1 \mathrm{M} \mathrm{KOH}+1 \mathrm{M}$ ethanol. The Pd nanoballs synthesized using swollen liquid crystals (SLCS) also exhibited better electro catalytic activity for ethanol oxidation in $1 \mathrm{M} \mathrm{KOH}$. Reprinted with permission from ref. 59. Copyright 2009 American Chemical Society.

Table 1 Comparison of the electrochemical performance of Pd nanostructured catalysts for the oxidation of ethanol: Pd nanoplates, Pd nanowires and Pd nanoballs reproduced from ref. 84 with permission from Elsevier

\begin{tabular}{|c|c|c|c|c|c|c|}
\hline $\begin{array}{l}\text { Materials } \\
\text { (after } 50 \text { cycles) }\end{array}$ & $\begin{array}{l}j_{\mathrm{pf}}(\text { forward anodic } \\
\text { peak current density) } \\
{\left[\mathrm{A} \mathrm{cm}^{-2}\left(\mathrm{mg}^{-1} \text { of Pd)] }\right.\right.}\end{array}$ & $\begin{array}{l}j_{\mathrm{pf}} / j_{\mathrm{pb}}(\text { backward } \\
\text { peak current } \\
\text { density) }\end{array}$ & $\begin{array}{l}E_{\text {onset }} \text { onset potentials } \\
\text { of the faradaic } \\
\text { current }(\mathrm{V} v s . \mathrm{Hg} / \mathrm{HgO})\end{array}$ & $\begin{array}{l}E_{\mathrm{pf}}(\text { potentials } \\
\text { corresponding } \\
\text { to the maxima } \\
\text { of the forward peak) } \\
\text { (V vs. } \mathrm{Hg} / \mathrm{HgO})\end{array}$ & $\begin{array}{l}E_{\mathrm{pb}}(\text { backward } \\
\text { peak currents) } \\
(\mathrm{V} v s . \mathrm{Hg} / \mathrm{HgO})\end{array}$ & Ref. \\
\hline $\begin{array}{l}\text { Pd nanoplates + PDPB } \\
\text { nanofibers }\end{array}$ & 4.5 & 1.95 & -0.570 & -0.174 & -0.297 & 84 \\
\hline Pd nanowires + Nafion & 2 & 1 & -0.664 & -0.166 & -0.278 & 72 \\
\hline Pd nanoballs + Nafion & 0.12 & 1.17 & -0.550 & -0.151 & -0.296 & 76 \\
\hline
\end{tabular}


diphenylbutadiyne (PDPB) nanofibers exhibit highly active, stable catalysis for the ethanol oxidation. ${ }^{\mathbf{8 4}}$ The nanocomposites showed excellent catalytic activity in direct alcohol oxidation due to its high surface area, better conductivity and mass transport. The nanocomposites was synthesized using swollen liquid crystals (SLCs) containing 1,4-diphenylbutadiyne (DPB) as monomer and PdII(acac $)_{2}$ as metal precursors source and the electro catalyst showed better electro catalytic activity. Comparison is made among other Pd nanostructures as in Table 1. It's shown that the Pd nanoplates synthesized using SLCs showed better electrocatalytic activity among other Pd nanostructures such as Pd nanowires, Pd nanoballs. ${ }^{84}$ Hence conducting polymers supported Pd nanostructures synthesized using swollen liquid crystals (SLCs) acts as better electrocatalyst for fuel cells applications.

Bimetallic nanostructures have often better performance in sensing, catalysis, electrolysis and storage application than monometallic nanostructures. ${ }^{85-87}$ Bimetallic $\mathrm{Pd}_{\text {shell }}-\mathrm{Au}_{\text {core }}$ nanostructures were also synthesized in soft template confinement provided by the cetyl trimethylammonium bromide
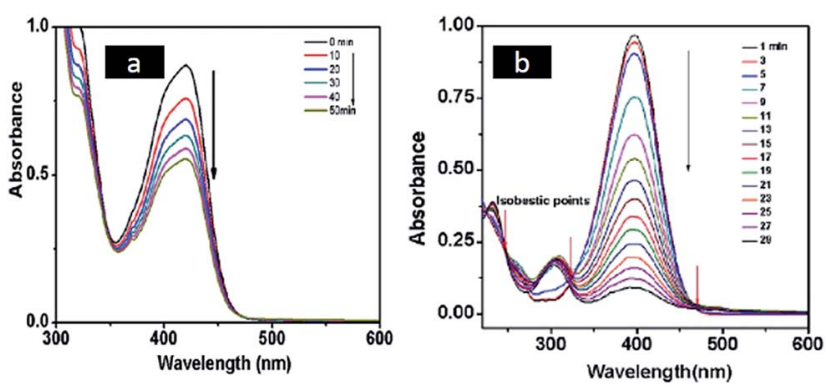

Fig. 34 (a) Time dependent UV-vis spectra at different reaction times for the electron transfer reaction between hexacyanoferrate(III) and sodium thiosulfate in the presence of platinum nanoballs (PtNBs) (b) UV-vis absorption spectra at different time intervals indicate the disappearance of the peak of $p$-nitrophenolate anion at $400 \mathrm{~nm}$ due to the reduction of $p$-nitrophenol (PNP) to $p$-aminophenol (PAP) by $\mathrm{NaBH}_{4}$ in the presence of platinum nanonets (PtNNs). Reprinted with permission from ref. 73. Copyright 2013 American Chemical Society.
(CTAB) surfactant using radiolytic method for synthesis. The synthesized nanostructures showed application in fuel cells with very good electrochemical activity and stability as shown in Fig. $33 .{ }^{59}$

In comparison, the $I_{\mathrm{f}}$ (forward current) $/ I_{\mathrm{b}}$ (backward current) ratio seems to be better 1.05 obtained with $\mathrm{Pd}-\mathrm{Au}_{\text {meso nano- }}$ structures Pd@Au/C nanostructures (0.69). ${ }^{\mathbf{8 8}}$ Hence the Pd$\mathrm{Au}_{\text {meso }}$ nanostructures synthesized using swollen liquid crystals (SLCs) shows better performance for ethanol electrooxidation.

\subsection{Pollutant degradation}

Catalytic activity of metal nanostructures synthesized using swollen liquid crystals (SLCs) were also explored for pollutant degradation. Platinum nanonets (PtNNs) and platinum nanoballs (PtNBs) were synthesized in swollen liquid crystals (SLCs) using radiolysis. ${ }^{73}$ In their typical synthesis swollen liquid crystals (SLCs) were doped with $\mathrm{Pt}\left(\mathrm{NH}_{3}\right)_{4} \mathrm{Cl}_{2}$. Swollen liquid crystals (SLCs) containing Pt salt was exposed with $\gamma$-rays and dose rate was $40 \mathrm{kGy}$ for platinum nanonets (PtNNs) and $80 \mathrm{kGy}$ for platinum nanoballs (PtNBs). The synthesized Pt nanostructures were studied for their catalytic degradation to hexacyanoferrate(III) and p-nitrophenol (PNP) as shown in Fig. 34.

Pd nanowires synthesized using swollen liquid crystals (SLCs) as soft template also exhibited better catalytic activity for $p$-nitrophenol reduction among others as shown in comparison Table $2 .^{89}$

Gold $_{\text {core-polyaniline }}$ shell composite nanowires were also reported first time in the literature. ${ }^{83}$ In typical synthesis of this unique nanocomposites the aniline monomer was trapped inside the swollen liquid crystals (SLCs) and on other hand, gold chloride metal salt as precursor was also trapped inside the swollen liquid crystals (SLCs) in different Pyrex glass tubes. After swollen liquid crystals (SLCs) synthesis, the both phases were allowed for slow diffusion over each other and due to polymerization, gold core- polyaniline shell $_{\text {was }}$ synthesized. The synthesized nanocomposites showed better performance for dye degradation applications as shown in Table 3 and Fig. 35.

Table 2 Comparison of apparent rate constants for 4-nitrophenol reduction with different reported catalyst systems. Reproduced from ref. 89 with permission from Elsevier

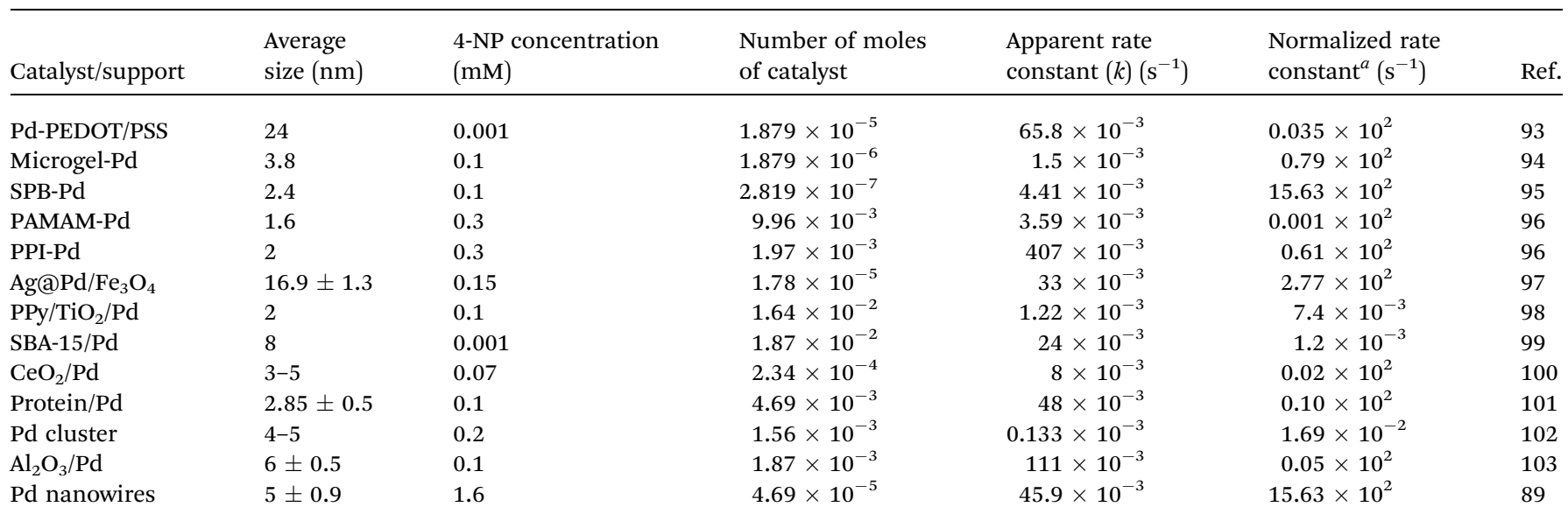

${ }^{a}$ Rate constant per moles of catalyst available per mM of 4-NP. 
Table 3 A comparison of catalytic activities of different catalysts that are reported in literature with the gold core -polyaniline shell $_{\text {composite }}$ nanowires for the chemical reduction of $\mathrm{MB}$ and RhB [reproduced from ref. 83 with permission from the Centre National de la Recherche Scientifique (CNRS) and The Royal Society of Chemistry]

\begin{tabular}{|c|c|c|c|}
\hline Catalyst & $T_{\text {completion } \mathrm{RhB} / \mathrm{min}}$ & $T_{\text {completion } \mathrm{MB} / \mathrm{min}}$ & Ref. \\
\hline $\begin{array}{l}\mathrm{Au} \text {-loaded } \mathrm{Fe}_{3} \mathrm{O}_{4} @ \mathrm{C} \text { composite } \\
\text { microspheres }\end{array}$ & & 10 & 103 \\
\hline Ag nanoparticles on silica spheres & & 7.5 & 104 \\
\hline $\mathrm{Fe}_{3} \mathrm{O}_{4} @ P A N I @ A u$ nanocomposites & 18 & & 105 \\
\hline Au-PANI nanocomposite & 15 & & 106 \\
\hline $\mathrm{Au}_{\text {core }}-\mathrm{PANI}_{\text {shell }}$ nanocomposite & 6 & 5 & 83 \\
\hline
\end{tabular}
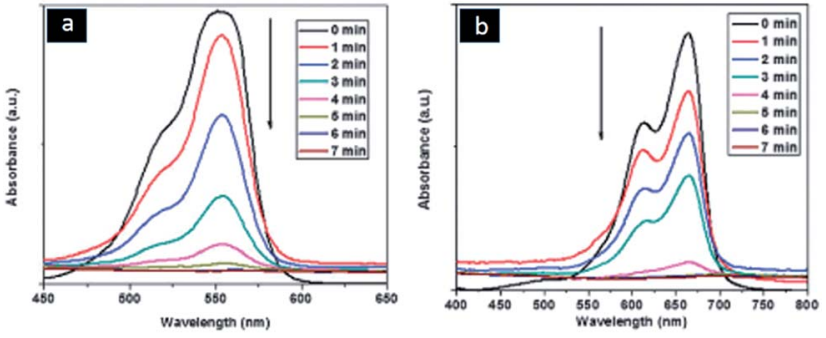

Fig. 35 Time dependent UV-visible spectra of rhodamine $B(\mathrm{RhB})$ and methylene blue (MB) showing the progress of dye reduction by $\mathrm{NaBH}_{4}$ nanocomposite in presence of gold $_{\text {core-polyaniline }}$ shell nanocomposites recorded at 1 min intervals. Reproduced from ref. 83 with permission from the Centre National de la Recherche Scientifique (CNRS) and The Royal Society of Chemistry.

\subsection{Coupling reactions}

Palladium nanowires synthesized using swollen liquid crystals (SLCs) as structure directing template were shown better catalytic activity in carbon-carbon $(\mathrm{C}-\mathrm{C})$ coupling organic reactions. ${ }^{89}$ The synthesized $\mathrm{Pd}$ nanowires using swollen liquid crystals (SLCs) were used as catalysts in Suzuki-Miyaura coupling reactions and showed better performance among others as shown in Table 4 . The progress of the reaction was initially monitored using TLC and the final extracted product was studied using NMR technique.

\subsection{Glucose bio sensing}

Spherical and one dimensional polyaniline (PANI) nanostructures were synthesized using swollen liquid crystals (SLCs) as soft templates. ${ }^{77}$ The glucose biosensing applications of the synthesized nanostructures were studied and the polyaniline (PANI) nanostructures showed better sensing property than bulk polyaniline (PANI) (prepared without any template) as shown in Fig. 36.

\subsection{Photocatalysis}

One-dimensional poly(diphenylbutadiyne) nanostructures were synthesized by photopolymerization using swollen liquid crystals (SLCs) as soft templating confinement. The synthesized nanostructures have high photocatalytic activity under visible light without the assistance of sacrificial reagents or precious metal co-catalysts as shown in Fig. $37 .^{91}$

Poly(3,4-ethylenedioxythiophene) (PEDOT) nanostructures synthesized in swollen liquid crystals (SLCs) as soft templates via chemical oxidative polymerization showed better photocatalytic activities than $\mathrm{TiO}_{2}$ as shown in Fig. $38 .^{79}$ The poly $(3,4-$ ethylenedioxythiophene) (PEDOT) nanostructures were synthesized by trapping the 3,4-ethylenedioxythiophene (EDOT) monomer inside the mesophase and $\mathrm{FeCl}_{3}$ was used as oxidant for polymerization. ${ }^{79}$

Moreover, the photo catalytic activity of poly(3,4-ethylenedioxythiophene) (PEDOT) nanospindles synthesized using

Table 4 Comparison of reaction yields for Suzuki-Miyaura coupling reactions with different reported Pd based catalysts reproduced from ref. 89 with permission from Elsevier

\begin{tabular}{|c|c|c|c|c|c|c|c|c|}
\hline Catalyst/support & Base & $\begin{array}{l}\text { Average } \\
\text { size (nm) }\end{array}$ & $\begin{array}{l}\text { Yield } \\
(\%)\end{array}$ & Temperature $/{ }^{\circ} \mathrm{C}$ & (Solvent) & $\begin{array}{l}\text { Reaction } \\
\text { time/h }\end{array}$ & $\begin{array}{l}\text { Catalyst } \\
\text { conc./mol\% }\end{array}$ & Ref. \\
\hline $\begin{array}{l}\text { PVP stabilized Pd } \\
\text { nanoparticles }\end{array}$ & $\mathrm{Na}_{3} \mathrm{PO}_{4}$ & $3-4$ & 92 & Reflux & $\begin{array}{l}40 \% \text { EtOH aqueous } \\
\text { solution }\end{array}$ & $12 \mathrm{~h}$ & $0.3 \mathrm{~mol} \% \mathrm{pd}$ & 107 \\
\hline $\begin{array}{l}\text { Polyaniline/Pd } \\
\text { nanocomposites }\end{array}$ & $\mathrm{K}_{3} \mathrm{PO}_{4}$ & $4-6$ & 85 & $100^{\circ} \mathrm{C}$ & 1,4-Dioxane & $15 \mathrm{~h}$ & $1.0 \mathrm{~mol} \%$ & 108 \\
\hline $\begin{array}{l}\text { Polyaniline/Pd } \\
\text { nanocomposites }\end{array}$ & $\mathrm{K}_{2} \mathrm{CO}_{3}$ & $3.1 \pm 0.9$ & 86 & $90^{\circ} \mathrm{C}$ & $\mathrm{H}_{2} \mathrm{O}$ & $4 \mathrm{~h}$ & $\begin{array}{l}0.01 \mathrm{~mol} \% \\
\text { PANI-Pd }\end{array}$ & 109 \\
\hline Pd nanowires & $\begin{array}{l}\text { Sodium } \\
t \text {-butoxide }\end{array}$ & 5 (diameter) & 99 & $\mathrm{RT}$ & $\mathrm{H}_{2} \mathrm{O}$ & $24 \mathrm{~h}$ & $6.5 \mathrm{~mol} \% \mathrm{Pd}$ & 111 \\
\hline Hollow Pd spheres & $\mathrm{K}_{3} \mathrm{PO}_{4}$ & 300 & 99 & $78{ }^{\circ} \mathrm{C}$ reflux & EtOH & $3 \mathrm{~h}$ & $3 \mathrm{~mol} \% \mathrm{Pd}$ & 112 \\
\hline Pd nanorods & $\mathrm{K}_{3} \mathrm{PO}_{4}$ & 20 (diameter) & 92 & $85^{\circ} \mathrm{C}$ reflux & EtOH : $\mathrm{H}_{2} \mathrm{O}(4: 1)$ & $4 \mathrm{~h}$ & $1.6 \mathrm{~mol} \%$ & 113 \\
\hline Pd nanowires & $\mathrm{K}_{2} \mathrm{CO}_{3}$ & 3-8 (diameter) & 80 & $90^{\circ} \mathrm{C}$ & Toluene & $9 \mathrm{~h}$ & $0.01 \mathrm{~mol} \%$ & 89 \\
\hline
\end{tabular}



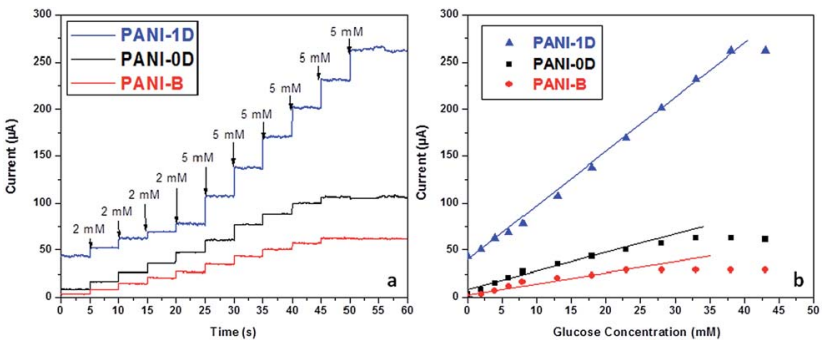

Fig. 36 (a) Chronoamperometric response of polyaniline (PANI) nanostructures synthesized using swollen liquid crystals (SLCs) and bulk polyaniline (PANI) with varying concentration of glucose in PBS buffer ( $\mathrm{pH}=7.2$ ) (b) calibration curves corresponding to the chronoamperometric glucose detection. Adapted with permission from ref. 90, copyright 2015, Biointerface Research in Applied Chemistry.
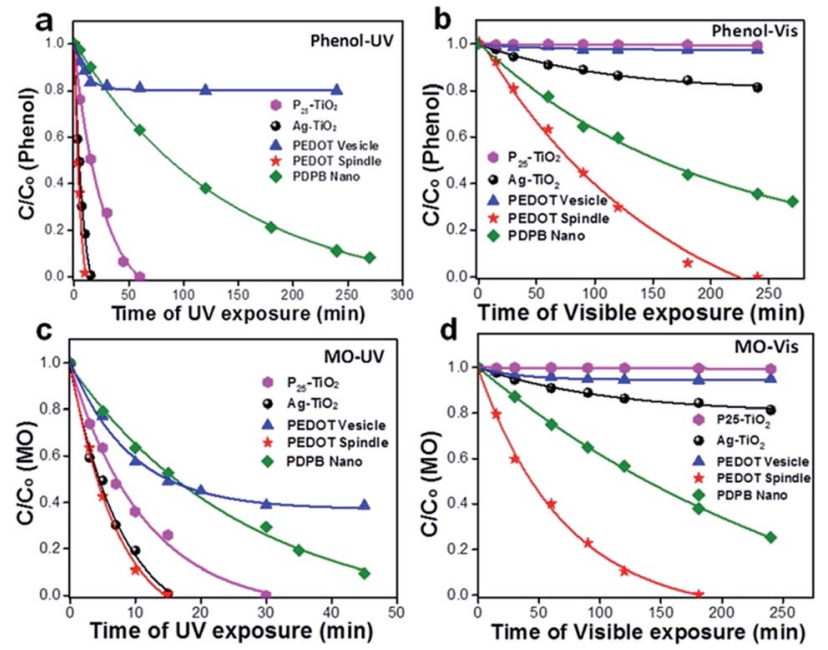

Fig. $37(a-d)$ Photocatalytic degradation of methyl orange ( $a$ and b) and phenol ( $c$ and d) in the presence of commercial P25 $\mathrm{TiO}_{2}, \mathrm{Ag}-\mathrm{TiO}_{2}$ and the synthesized bulk poly(diphenylbutadyine) (PDPB) and nano poly(diphenylbutadyine) (PDPB). (a and c) Degradation carried out under visible light (>450 nm). (b and d) Degradation carried out under ultraviolet light. The concentrations of nano poly(diphenylbutadyine) (PDPB), bulk poly(diphenylbutadyine) (PDPB), $\mathrm{Ag}-\mathrm{TiO}_{2}$ and $\mathrm{TiO}_{2}$ in water were $1 \mathrm{mg} \mathrm{mL}^{-1}$. Initial concentrations $C_{0}$ were $6 \times 10^{-5} \mathrm{~mol} \mathrm{~L}^{-1}$ for methyl orange $(\mathrm{MO})$ and $3.7 \times 10^{-3} \mathrm{~mol} \mathrm{~L}^{-1}$ for phenol. The legend in figure (a) applies to all panels. Reprinted by permission from Macmillan Publishers Ltd: Nature Materials, ${ }^{91}$ copyright (2015).

SLCs is much better than bulk poly(3,4-ethylenedioxythiophene) (PEDOT) and poly(diphenylbutadyine) (PDPB) nanofibers. ${ }^{92}$

\section{Future directions and prospectives}

Here, we have summarized the synthesis of different nanostructures using swollen liquid crystals (SLCs). Swollen liquid crystals (SLCs) acts as an efficient and versatile template for the synthesis of nanomaterials. The stability of swollen liquid crystals (SLCs) depends upon the chemical nature of the trapped components inside the nano channels, $\mathrm{pH}$, temperature etc. It is also shown that using swollen liquid crystals (SLCs), different types of nanostructures can be synthesized due to
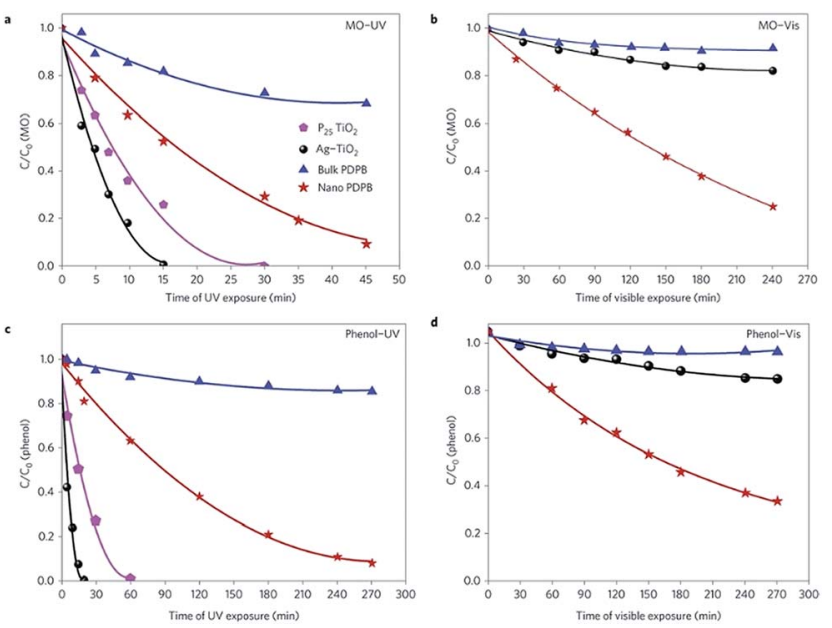

Fig. 38 Photocatalytic degradation of ( $a$ and b) phenol and (c and d) methyl orange (MO) in the presence of commercial P25 $\mathrm{TiO}_{2}$ and Ag$\mathrm{TiO}_{2}$, poly(diphenylbutadyine) (PDPB) nanofibers and the synthesized poly(3,4-ethylenedioxythiophene) (PEDOT) vesicles and poly(3,4-ethylenedioxythiophene) (PEDOT) nanospindles under UV ( $a$ and $c$ ) and visible light $(>450 \mathrm{~nm})$ (b and d) irradiation. The concentrations of poly (diphenylbutadyine) (PDPB) nanofibers, poly(3,4-ethylenedioxythiophene) (PEDOT) vesicles, poly(3,4-ethylenedioxythiophene) (PEDOT) nanospindles, $\mathrm{Ag}-\mathrm{TiO}_{2}$ and $\mathrm{TiO}_{2}$ in water were $1 \mathrm{mg} \mathrm{mL}^{-1}$. Initial concentrations $C_{0}$ were $3.7 \times 10^{-3} \mathrm{~mol} \mathrm{~L}^{-1}$ for phenol and $6 \times 10^{-5} \mathrm{~mol} \mathrm{~L}^{-1}$ for methyl orange (MO). Reprinted by permission from Macmillan Publishers Ltd: Scientific Reports, ${ }^{79}$ copyright (2015).

change of experimental parameters during swollen liquid crystals (SLCs) preparation. Hence, swollen liquid crystals (SLCs) as nano channels can be used as reacting media to perform different kind of reactions inside these channels. Nanostructures synthesis can also be done inside these nano channels. Swollen liquid crystals (SLCs) can be used for the synthesis of porous, zero dimensional, one dimensional nanostructures with tunable properties. These synthesized nanostructures have different applications such as in catalysis, electrocatalysis, sensing, fuel cells etc. The swollen liquid crystals (SLCs) will open up a new area of research because the reactions can be performed in aqueous phase or organic phase or potentially in both phases or eventually at the interface between the two phases. This should lead to the control of the morphology and then to the optimization of the properties of the as-synthesized nanomaterials.

\section{Acknowledgements}

S. D. is thankful to The Scientific and Technological Research Council of Turkey (TÜBİTAK) to support under 2216 fellowship grant for international Post-Doctoral researchers.

\section{References}

1 C. R. Martin, Chem. Mater., 1996, 8, 1739-1746.

2 X. Lu, C. Wang and Y. Wei, Small, 2009, 5, 2349-2370.

3 J. D. Schiffman and C. L. Schauer, Polym. Rev., 2008, 48, 317-352. 
4 J. C. Hulteen and C. R. Martin, J. Mater. Chem., 1997, 7, 1075-1087.

5 G. Cao and D. Liu, Adv. Colloid Interface Sci., 2008, 136, 45-64.

6 X. Chen and S. S. Mao, Chem. Rev., 2007, 107, 2891-2959.

7 G. Cao and D. Liu, Adv. Colloid Interface Sci., 2008, 136, 45-64.

8 M. A. Lopez-Quintela, Curr. Opin. Colloid Interface Sci., 2003, 8, 137-144.

9 X. Chen and S. S. Mao, Chem. Rev., 2007, 107, 2891-2959.

10 H. D. Tran, D. Li and R. B. Kaner, Adv. Mater., 2009, 21, 1487-1499.

11 P. F. Siril, L. Ramos, P. Beaunier, P. Archirel, A. Etcheberry and H. Remita, Chem. Mater., 2009, 21, 5170-5175.

12 L. Ramos and P. Fabre, Langmuir, 1997, 13, 682-686.

13 E. Pena dos Santos, M. S. Tokumoto, G. Surendran, H. Remita, C. Bourgaux, P. Dieudonné, E. Prouzet and L. Ramos, Langmuir, 2005, 21, 4362-4369.

14 L. Ramos and C. Ligoure, Langmuir, 2008, 24, 5221-5224. 15 K. Holmberg, J. Colloid Interface Sci., 2004, 274, 355-364.

16 J. N. Israelachvili, D. J. Mitchell and B. W. Ninham, J. Chem. Soc., Faraday Trans. 2, 1976, 72, 1525-1568.

17 J. Israelachvili, Colloids Surf., A, 1994, 91, l-8.

18 M. Salim, H. Minamikawa, A. Sugimura and R. Hashim, MedChemComm, 2014, 5, 1602-1618.

19 J. P. Hill, L. K. Shrestha, S. Ishihara, Q. Ji and K. Ariga, Molecules, 2014, 19, 8589-8609.

20 A. Brizard, M. Stuart, K. Bommel, A. Friggeri, M. Jong and J. Esch, Angew. Chem., Int. Ed., 2008, 47, 2063-2066.

21 G. Zhou, Y. Chen, J. Yang and S. Yang, J. Mater. Chem., 2007, 17, 2839-2844.

22 B. Sun, G. Zhou and H. Zhang, Prog. Solid State Chem., 2016, 44, 1-19.

23 X. Wang, J. Feng, Y. Bai, Q. Zhang and Y. Yin, Chem. Rev., 2016, 116, 10983-11060.

24 Q. Liu, Z. Sun, Y. Dou, J. H. Kim and S. X. Dou, J. Mater. Chem. A, 2015, 3, 11688-11699.

25 S. Saliba, C. Mingotaud, M. L. Kahn and J. D. Marty, Nanoscale, 2013, 5, 6641-6661.

26 F. C. Frank, Discuss. Faraday Soc., 1958, 25, 19-28.

27 A. Humpert, A. J. Masters and M. P. Allen, Eur. Phys. J.: Spec. Top., 2016, 225, 1723-1732.

28 P. S. Pershan, Phys. Today, 2008, 35, 34-39.

29 B. J. Forrest and L. W. Reeves, Chem. Rev., 1981, 81(1), 1-14.

30 W. Bryks, M. Wette, N. Velez, S. W. Hsu and A. R. Tao, J. Am. Chem. Soc., 2014, 136, 6175-6178.

31 S. Peng, Q. Guo, T. C. Hughes and P. G. Hartley, Langmuir, 2013, 30, 866-872.

32 T. M. Dellinger and P. V. Braun, Chem. Mater., 2004, 16, 2201-2207.

33 P. S. Pershan, Phys. Today, 1982, 35, 34-39.

34 C. Wang, D. Chen and X. Jiao, Sci. Technol. Adv. Mater., 2009, 10, 023001.

35 H. J. Coles and M. N. Pivnenko, Nature, 2005, 436, 997-1000. 36 J. Li, S. Gauza and S. T. Wu, J. Appl. Phys., 2004, 96, 19-24. 37 S. Bonazzi, M. Capobianco, M. M. D. Morais, A. Garbesi, G. Gottarelli, P. Mariani, M. G. P. Bossi, G. P. Spada and L. Tondelli, J. Am. Chem. Soc., 1991, 113(15), 5809-5816.
38 C. M. Paleos and D. Tsiourvas, Angew. Chem., Int. Ed. Engl., 1995, 34, 1696-1711.

39 T. Oka and N. Ohta, Langmuir, 2016, 32, 7613-7620.

40 C. Wang, D. Chen and X. Jiao, Sci. Technol. Adv. Mater., 2009, 10, 023001.

41 W. Abidi, B. Pansu, R. Krishnaswamy, P. Beaunier, H. Remita and M. Imperor-Clerc, RSC Adv., 2011, 1, 434439.

42 W. Abidi, P. Selvakannan, Y. Guillet, I. Lampre, P. Beaunier, B. Pansu, B. Palpant and H. Remita, J. Phys. Chem. C, 2010, 114, 14794-14803.

43 T. Kijima, T. Ikeda, M. Yada and M. Machida, Langmuir, 2002, 18, 6453-6457.

44 L. Huang, H. Wang, Z. Wang, A. Mitra, K. N. Bozhilov and Y. Yan, Adv. Mater., 2002, 14, 61.

45 H. Kawasaki, M. Uota, T. Yoshimura, D. Fujikawa, G. Sakai, M. Annaka and T. Kijima, Langmuir, 2005, 21, 11468-11473. 46 C. Kresge, M. Leonowicz, W. Roth, J. Vartuli and J. Beck, Nature, 1992, 359, 710-712.

47 L. Ramos and C. Ligoure, Langmuir, 2008, 24, 5221-5224.

48 G. Surendran, M. S. Tokumoto, E. Pena dos Santos, H. Remita, L. Ramos, P. J. Kooyman, C. V. Santilli, C. Bourgaux, P. Dieudonné and E. Prouzet, Chem. Mater., 2005, 17, 1505-1514.

49 G. Surendran, M. S. Tokumoto, E. P. Santos, H. Remita, L. Ramos, P. J. Kooyman, C. V. Santilli, C. Bourgaux, P. Dieudonne and E. Prouzet, Chem. Mater., 2005, 17, 1505-1514.

50 L. Ramos and P. Fabre, Langmuir, 1997, 13, 682-686.

51 E. Pena dos Santos, M. S. Tokumoto, G. Surendran, H. Remita, C. Bourgaux, P. Dieudonné, E. Prouzet and L. Ramos, Langmuir, 2005, 21, 4362-4369.

52 S. Dutt and P. F. Siril, Synth. Met., 2015, 209, 82-90.

53 E. Eiser, F. Bouchama, M. B. Thathagar and G. Rothenberg, ChemPhysChem, 2003, 4, 526-528.

54 S. Ghosh, H. Remita, L. Ramos, A. Dazzi, A. DenisetBesseau, P. Beaunier, F. Goubard, P.-H. Aubert, F. Brisset and S. Remita, New J. Chem., 2014, 38, 1106-1115.

55 A. Lehoux, L. Ramos, P. Beaunier, D. B. Uribe, P. Dieudonné, F. Audonnet, A. Etcheberry, M. JoséYacaman and H. Remita, Adv. Funct. Mater., 2012, 22, 4900-4908.

56 T. Redjala, G. Apostolecu, P. Beaunier, M. Mostafavi, A. Etcheberry, D. Uzio, C. Thomazeau and H. Remita, New J. Chem., 2008, 32, 1403-1408.

57 L. Ramos, P. Fabre and R. Ober, Eur. Phys. J. B, 1998, 1, 319326.

58 G. Surendran, L. Ramos, B. Pansu, E. Prouzet, P. Beaunier, F. Audonnet and H. Remita, Chem. Mater., 2007, 19, 50455048.

59 F. Ksar, L. Ramos, B. Keita, L. Nadjo, P. Beaunier and H. Remita, Chem. Mater., 2009, 21, 3677-3683.

60 P. Fabre, C. Casagrande, M. Veyssie, V. Cabuil and R. Massart, Phys. Rev. Lett., 1990, 64, 539.

61 C. Quilliet, P. Fabre and V. Cabuil, J. Phys. Chem., 1993, 97, 287-289. 
62 C. Quilliet, V. Ponsinet and V. Cabuil, J. Phys. Chem., 1994, 98, 3566-3569.

63 L. Ramos, P. Fabre and L. Fruchter, Eur. Phys. J. B, 1999, 8, 67-72.

64 L. Ramos, F. Molino and G. Porte, Langmuir, 2000, 16, 58465848.

65 N. Kinadjian, F. Nallet, I. Ly, A. Bentaleb, R. Backov and E. Prouzet, Liq. Cryst., 2016, 43, 615-622.

66 A. Thomas, F. Goettmann and M. Antonietti, Chem. Mater., 2008, 20, 738-755.

67 C. C. Yang, C. C. Wan and Y. Y. Wang, J. Colloid Interface Sci., 2004, 279, 433-439.

68 Q. Zhang, W. Wang, J. Goebl and Y. Yin, Nano Today, 2009, 4, 494-507.

69 H. D. Tran, D. Li and R. B. Kaner, Adv. Mater., 2009, 21, 1487-1499.

70 P. F. Siril, L. Ramos, P. Beaunier, P. Archirel, A. Etcheberry and H. Remita, Chem. Mater., 2009, 21, 5170-5175.

71 P. F. Siril, A. Lehoux, L. Ramos, P. Beaunier and H. Remita, New J. Chem., 2012, 36, 2135-2139.

72 F. Ksar, G. Surendran, L. Ramos, B. Keita, L. Nadjo, E. Prouzet, P. Beaunier, A. Hagege, F. Audonnet and H. Remita, Chem. Mater., 2009, 21, 1612-1617.

73 A. M. Kalekar, K. K. K. Sharma, A. Lehoux, F. Audonnet, H. Remita, A. Saha and G. K. Sharma, Langmuir, 2013, 29, 11431-11439.

74 H. Tang, G. Meng, Q. Huang, C. Zhu, Z. Huang, Z. Li, Z. Zhang and Y. Zhang, RSC Adv., 2014, 4, 19654-19657.

75 T. Arun, D. K. Chacko, A. A. Madhavan, T. Deepak, G. Anjusree, T. Sara, S. Ramakrishna, S. V. Nair and A. S. Nair, RSC Adv., 2014, 4, 1421-1424.

76 G. Surendran, F. Ksar, L. Ramos, B. Keita, L. Nadjo, E. Prouzet, P. Beaunier, P. Dieudonné, F. Audonnet and H. Remita, J. Phys. Chem. C, 2008, 112, 10740-10744.

77 S. Dutt and P. F. Siril, J. Appl. Polym. Sci., 2014, 131, 40800.

78 E. P. Santos, C. V. Santilli, S. H. Pulcinelli and E. Prouzet, Chem. Mater., 2004, 16, 4187-4192.

79 S. Ghosh, N. A. Kouame, S. Remita, L. Ramos, F. Goubard, P. H. Aubert, A. Dazzi, A. Deniset-Besseau and H. Remita, Sci. Rep., 2015, 5, 18002.

80 D. U. Lee, D. Pradhan, R. Mouawia, D. H. Oh, N. F. Heinig, K. T. Leung and E. Prouzet, Chem. Mater., 2009, 22, 218225.

81 S. Dutt and P. F. Siril, Mater. Lett., 2014, 124, 50-53.

82 S. Ghosh, L. Ramos, S. Remita, A. Dazzi, A. Deniset-Besseau, P. Beaunier, F. Goubard, P. H. Aubert and H. Remita, New J. Chem., 2015, 39, 8311-8320.

83 S. Dutt, P. F. Siril, V. Sharma and S. Periasamy, New J. Chem., 2015, 39, 902-908.

84 S. Ghosh, A. L. Teillout, D. Floresyona, P. de Oliveira, A. Hagège and H. Remita, Int. J. Hydrogen Energy, 2015, 40, 4951-4959.

85 H.-L. Jiang and Q. Xu, J. Mater. Chem., 2011, 21, 1370513725.

86 D. Wang and Y. Li, Adv. Mater., 2011, 23, 1044-1060.
87 R. P. Doherty, J. M. Krafft, C. Méthivier, S. Casale, H. Remita, C. Louis and C. Thomas, J. Catal., 2012, 287, 102-113.

88 L. D. Zhu, T. S. Zhao, J. B. Xu and Z. X. Liang, J. Power Sources, 2009, 187, 80.

89 M. Chawla, R. Kumar and P. F. Siril, J. Mol. Catal. A: Chem., 2016, 423, 126-134.

90 S. Dutt and P. F. Siril, Biointerface Res. Appl. Chem., 2015, 5(2), 937-940.

91 S. Ghosh, N. A. Kouamé, L. Ramos, S. Remita, A. Dazzi, A. Deniset-Besseau, P. Beaunier, F. Goubard, P. H. Aubert and H. Remita, Nat. Mater., 2015, 14, 505-511.

92 Z. Yin and Q. Zheng, Adv. Energy Mater., 2012, 2, 179-218.

93 S. Harish, J. Mathiyarasu, K. Phani and V. Yegnaraman, Catal. Lett., 2009, 128, 197-202.

94 Y. Mei, Y. Lu, F. Polzer, M. Ballauff and M. Drechsler, Chem. Mater., 2007, 19, 1062-1069.

95 K. Esumi, R. Isono and T. Yoshimura, Langmuir, 2004, 20, 237-243.

96 K. Jiang, H. X. Zhang, Y. Y. Yang, R. Mothes, H. Lang and W. B. Cai, Chem. Commun., 2011, 47, 11924-11926.

97 X. Lu, X. Bian, G. Nie, C. Zhang, C. Wang and Y. Wei, J. Mater. Chem., 2012, 22, 12723-12730.

98 J. Morere, M. Tenorio, M. Torralvo, C. Pando, J. Renuncio and A. Cabanas, J. Supercrit. Fluids, 2011, 56, 213-222.

99 B. Liu, S. Yu, Q. Wang, W. Hu, P. Jing, Y. Liu, W. Jia, Y. Liu, L. Liu and J. Zhang, Chem. Commun., 2013, 49, 3757-3759.

100 S. Behrens, A. Heyman, R. Maul, S. Essig, S. Steigerwald, A. Quintilla, W. Wenzel, J. Bürck, O. Dgany and O. Shoseyov, Adv. Mater., 2009, 21, 3515-3519.

101 A. Halder, S. Patra, B. Viswanath, N. Munichandraiah and N. Ravishankar, Nanoscale, 2011, 3, 725-730.

102 S. Arora, P. Kapoor and M. L. Singla, React. Kinet., Mech. Catal., 2010, 99, 157-165.

103 Z. Gan, A. Zhao, M. Zhang, W. Tao, H. Guo, Q. Gao, R. Mao and E. Liu, Dalton Trans., 2013, 8597-8605.

104 Z. J. Jiang, C. Y. Liu and L. W. Sun, J. Phys. Chem. B, 2005, 109, 1730-1735.

105 S. Xuan, Y. X. J. Wang, J. C. Yu and K. C. F. Leung, Langmuir, 2009, 25, 11835-11843.

106 B. Zhang, B. Zhao, S. Huang, R. Zhang, P. Xu and H. L. Wang, CrystEngComm, 2012, 14, 1542-1544.

107 Y. Li, X. M. Hong, D. M. Collard and M. A. El-Sayed, Org. Lett., 2000, 2, 2385-2388.

108 A. Houdayer, R. Schneider, D. Billaud, J. Ghanbaja and J. Lambert, Appl. Organomet. Chem., 2005, 19, 1239-1248.

109 S. Dutt, R. Kumar and P. F. Siril, RSC Adv., 2015, 5, 3378633791.

110 J. Yang, D. Wang, W. Liu, X. Zhang, F. Bian and W. Yu, Green Chem., 2013, 15, 3429-3437.

111 C. Jiang, S. Ranjit, Z. Duan, Y. L. Zhong, K. P. Loh, C. Zhang and X. Liu, Nanoscale, 2009, 1, 391-394.

112 S. W. Kim, M. Kim, W. Y. Lee and T. Hyeon, J. Am. Chem. Soc., 2002, 124, 7642-7643.

113 Y. H. Chen, H. H. Hung and M. H. Huang, J. Am. Chem. Soc., 2009, 131, 9114-9121. 